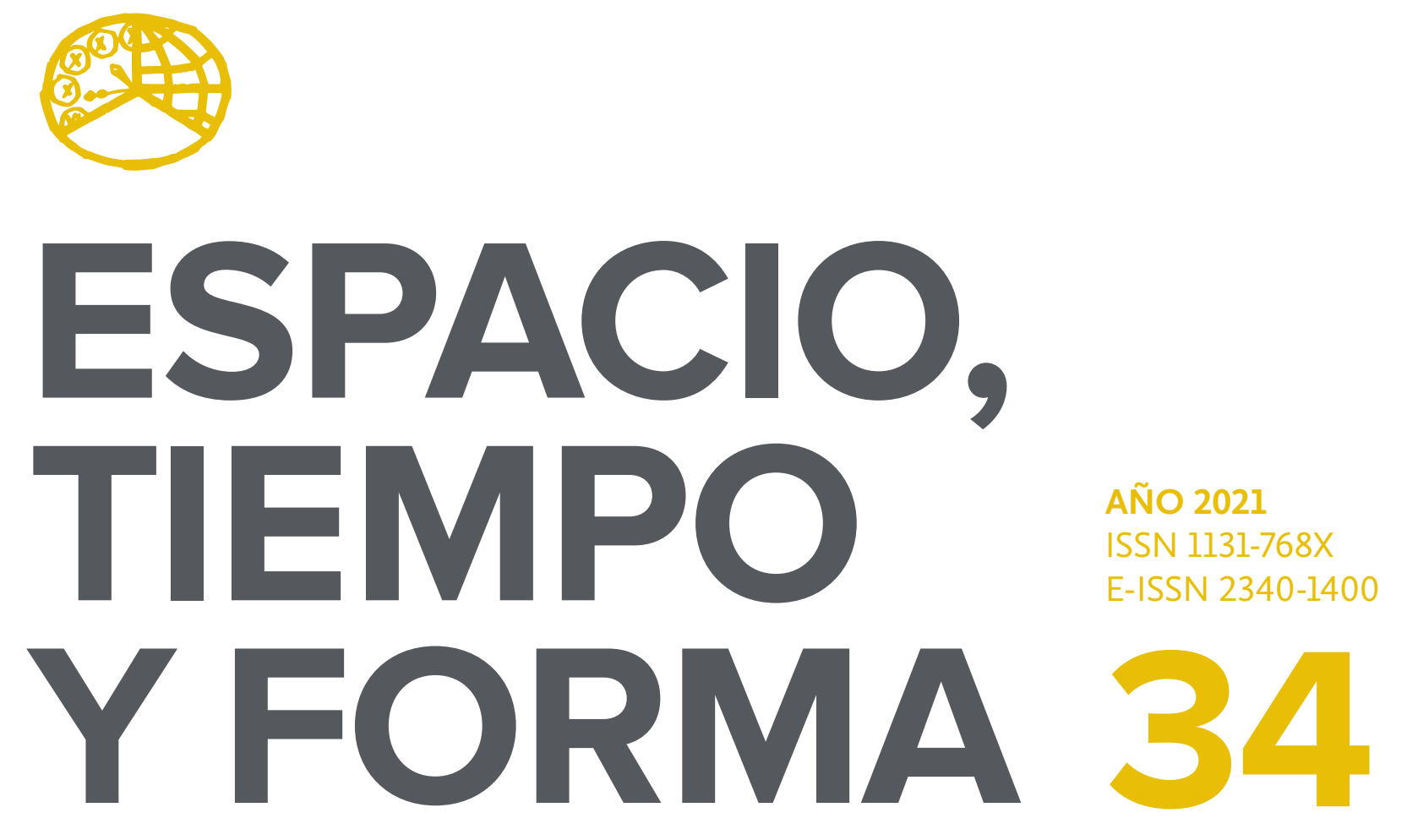

SERIE IV HISTORIA MODERNA

REVISTA DE LA FACULTAD DE GEOGRAFÍA E HISTORIA

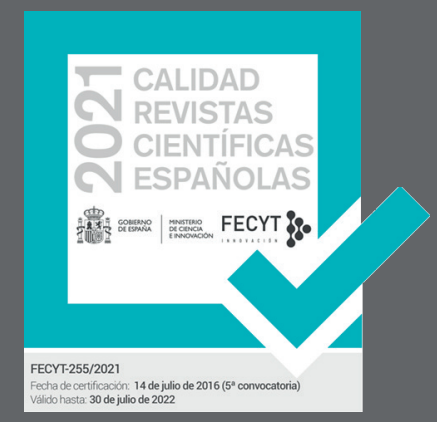




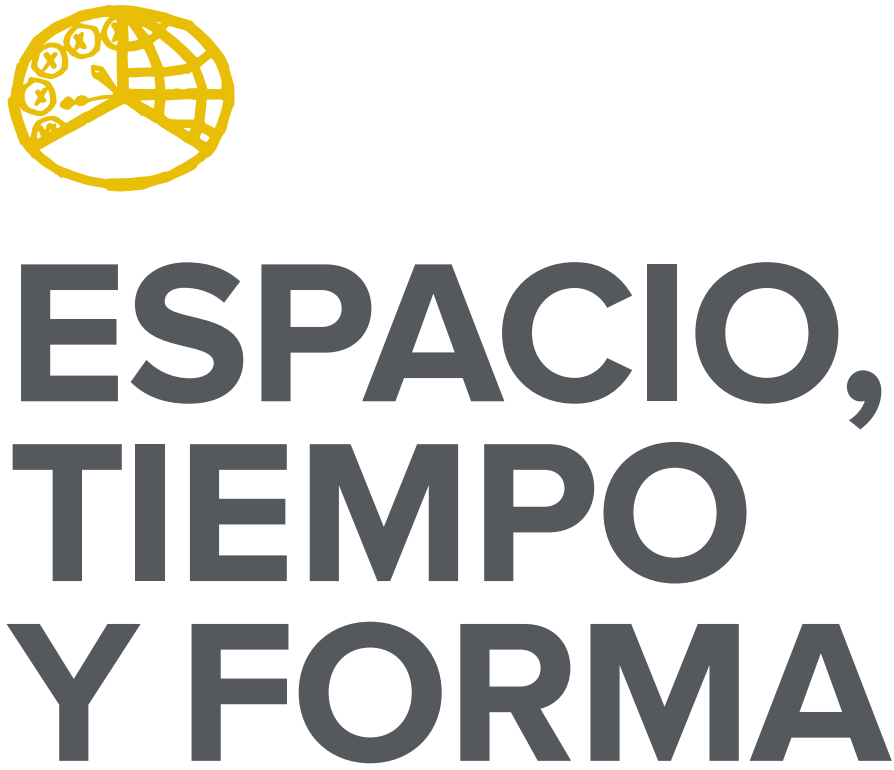

AÑO 2021

ISSN 1131-768X

E-ISSN 2340-1400

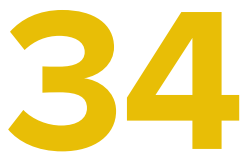

SERIE IV HISTORIA MODERNA

REVISTA DE LA FACULTAD DE GEOGRAFÍA E HISTORIA

DOI: https://doi.org/10.5944/etfiv.34.2021

\section{UกED}

UNIVERSIDAD NACIONAL DE EDUCACIÓN A DISTANCIA 
La revista Espacio, Tiempo y Forma (siglas recomendadas: ETF), de la Facultad de Geografía e Historia de la UNED, que inició su publicación el año 1988, está organizada de la siguiente forma:

$$
\begin{aligned}
& \text { SERIE I - Prehistoria y Arqueología } \\
& \text { SERIE II - Historia Antigua } \\
& \text { SERIE III - Historia Medieval } \\
& \text { SERIE IV - Historia Moderna } \\
& \text { SERIE V - Historia Contemporánea } \\
& \text { SERIE VI - Geografía } \\
& \text { SERIE VII - Historia del Arte }
\end{aligned}
$$

Excepcionalmente, algunos volúmenes del año 1988 atienden a la siguiente numeración:

$$
\begin{aligned}
& \mathrm{N} .^{\circ} 1 \text { - Historia Contemporánea } \\
& \mathrm{N}^{\circ} 2 \text { - Historia del Arte } \\
& \mathrm{N} .^{\circ} 3 \text { - Geografía } \\
& \mathrm{N} .^{\circ} 4 \text { - Historia Moderna }
\end{aligned}
$$

ETF no se solidariza necesariamente con las opiniones expresadas por los autores.

\author{
UNIVERSIDAD NACIONAL DE EDUCACIÓN A DISTANCIA \\ Madrid, 2021 \\ SERIE IV · HISTORIA MODERNA N. ${ }^{\circ} 34,2021$ \\ ISSN $1131-768 X \cdot$ E-ISSN 2340-1400 \\ DEPÓSITO LEGAL \\ M-21.037-1988 \\ URL \\ ETF IV · HISTORIA MODERNA · http://revistas.uned.es/index.php/ETFIV \\ DISEÑO Y COMPOSICIÓN \\ Carmen Chincoa Gallardo · http://www.laurisilva.net/cch \\ Impreso en España · Printed in Spain
}

(c) (7) (8) Esta obra está bajo una licencia Creative Commons Reconocimiento-NoComercial 4.0 Internacional. 


\section{MISCELÁNEA • MISCELLANY}





\title{
CRIADOS, JORNALEROS Y ESCLAVOS AL SERVICIO DE LA FAMILIA: LA SERVIDUMBRE DE LOS MUÑOZ DE OTÁLORA EN EL SIGLO XVII
}

\section{SERVANTS, DAY LABORERS AND SLAVES: THE SERFDOM OF THE MUÑOZ DE OTÁLORA IN THE 17TH CENTURY}

José Antonio Martínez Martínez ${ }^{1}$

Recibido: 11/06/2021 - Aceptado: 20/09/2021

DOI: https://doi.org/10.5944/etfiv.34.2021.28576

\begin{abstract}
Resumen
Los criados y siervos, además de tener un claro componente funcional y utilitario, eran un símbolo de ostentación y de honra en el entramado social del Antiguo Régimen. Formaban parte de la familia y eran un elemento esencial en la administración de la hacienda y la casa. En este trabajo se intenta estudiar la servidumbre a través de las prácticas de la familia Muñoz de Otálora, prestando especial atención a los jornaleros, a los arrieros, a los mayorales y administradores, así como a las amas de cría y a los esclavos.
\end{abstract}

Palabras clave

Criados; esclavos; jornaleros; amas; Muñoz de Otálora

\section{Abstract}

The breeders and servants, in addition to having a clear functional and utilitarian component, were a symbol of ostentation and honor in the social fabric of the Old Regime. They were part of the family and were an essential element in the administration of the property and the house. This work attempts to study serfdom through the practices of the Muñoz de Otálora family, paying special attention to the day laborers, muleteers, mayor and administrators, as well as nursing maids and slaves.

Keywords

Servants; slaves; day laborers; housekeepers; Muñoz de Otálora

1. Universidad de Murcia;jmm70462@um.es

Archivo General de Murcia [AGM]. Archivo Real Chancillería de Granada [ARChG]. 


\section{INTRODUCCIÓN}

Las diversas interpretaciones conceptuales relativas al linaje, a la casa y a las familias nobiliarias, caso de los Muñoz de Otálora, abren diversos abanicos interpretativos y analíticos desde el punto de vista historiográfico. El linaje, según las definiciones aportadas por los tratadistas, se puede interpretar como un grupo familiar extenso de descendencia unilineal que engloba diferentes casas y familias ${ }^{2}$. La casa hace referencia a un grupo familiar más cercano y restringido, casi equivalente al concepto de familia nuclear, ${ }^{3}$ que se incardina dentro del linaje y lo usa para justificar y legitimar su posición social privilegiada ${ }^{4}$. La casa se va construyendo mediante la sucesiva y continua agregación de capital honorífico (hidalguías y títulos nobiliarios), de patrimonio material (mayorazgos y vínculos) y de patrimonio inmaterial (empleos honoríficos, etc.)

Existe una estrecha relación entre casa y familia, una disparidad de los roles en las funciones y cometidos que cada cual desempeña y un sentido amplio en relación a los componentes y miembros que la articulan e integran: el cabeza de familia, la esposa, los hijos, los criados y los esclavos 5 . El patriarca era el responsable del cuidado y del control de las personas asociadas a la casa ${ }^{6}$. Los diversos estudios sobre la historia de la familia ${ }^{7}$, además de influir en la metodología de la historia social ${ }^{8}$, evidenciaron que los criados y esclavos eran componentes del núcleo familiar y que incluso compartían vivienda con sus amos ${ }^{9}$. De hecho, los criados formaban parte de la familia, aunque no vivieran físicamente dentro de los muros de la casa ${ }^{\text {io }}$. En el ámbito Mediterráneo ${ }^{\text {II }}$, a diferencia del modelo social de la Europa noroccidental, también se percibían como criados a aquellos que tenían su propia familia y no vivían en la casa de sus amos, independientemente de los tipos de servicios que prestaran ${ }^{12}$.

El presente estudio se centra en las prácticas concretas de la familia Muñoz de Otálora. Se trata de la familia más poderosa y rica de la villa de Caravaca, cabeza de encomienda santiaguista en el noroeste del reino de Murcia, tanto en el plano económico, como en el plano social y relacional. El poder económico de la familia se sustentaba en tres pilares básicos: la ganadería, la imposición de censos y juros y la explotación agraria. Se trata de una familia inserta en un linaje (Musso Muñoz) que articulaba una gran y sólida red social y política en los concejos de Caravaca, Lorca y Murcia. Aunque se perdieron en las líneas femeninas, su importante inyección patrimonial permitió a muchas otras familias obtener títulos nobiliarios en el siglo XVIII. Por otro lado, los objetivos fundamentales de este artículo son

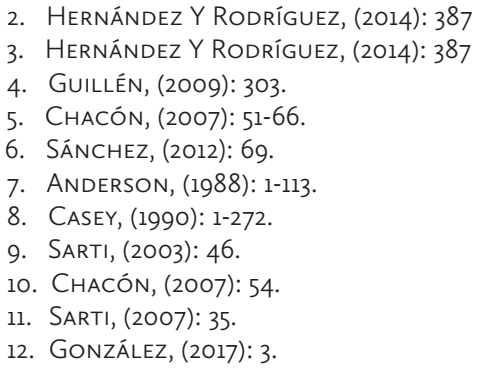


evidenciar las diferencias entre los diversos tipos de siervos que asistían a las familias nobiliarias. Mostrar que los mayorales, los pastores y los jornaleros con frecuencia permanecían durante generaciones al servicio de la familia mediante lazos clientelares y de patronazgo y, finalmente, analizar el papel de los esclavos en el seno familiar. Por otro lado, nuestra intención es precisar que los criados y esclavos formaban parte de la casa y, además de ser esenciales elementos productivos de las economías nobiliarias, eran símbolos de estatus y de ostentación social. También pretendemos ilustrar los procesos de ascenso en la servidumbre.

Los trabajos más recientes relativos al trabajo doméstico se centran en el estudio el ciclo de vida de los individuos, tratando de detectar el tipo de relaciones establecidas entre amos y criados, en la corresidencia, en los lazos familiares ${ }^{13}$, en el tipo de profesión y en los periodos de trabajo (temporal o permanente). Diversos autores consideran que en algunas ocasiones la servidumbre tan solo sería algo temporal, caso de los inmigrantes que finalmente acababan integrándose en la sociedad como asalariados $^{\mathrm{I}}$. En España, sin embargo, a diferencia de lo que sucedía en los países del norte de Europa, el servicio doméstico era una verdadera forma de vida para muchas mujeres ${ }^{15}$.

Desde la perspectiva funcional y residencial, existen dos peculiaridades que permiten diferencias a los criados del resto de trabajadores de una casa: por un lado, los agregados domésticos que viven bajo el mismo techo y se sustentan con los mismos medios que los familiares del amo; por otro, los que trabajan alrededor de una casa pero no forman parte del grupo que atiende las necesidades más inmediatas e íntimas de la familia ${ }^{16}$. Al primer grupo pertenecen los asalariados domésticos y todos aquellos que mantienen largas relaciones contractuales (mayordomos, amas de llaves, amas de cría, personal de servicio, pajes etc.) con los amos. En un punto intermedio podemos situar a los pastores, a los arrieros, a los maestros de carros, etc. que solían permanecer durante años al servicio de la familia y en ocasiones mantenían relaciones muy cercanas con los amos. El segundo tipo engloba a los jornaleros y peones agrarios que mantienen relaciones contractuales estacionales o esporádicas con los señores. En algunas ocasiones permanecían durante varias generaciones laborando las tierras de la familia. Nos encontramos, evidentemente, ante una relación clientelar y de patronazgo, en ningún caso ante un tipo de adscripción feudal a la tierra.

También es necesario diferenciar entre criados de servicio personal, encargados de la asistencia más íntima y criados encargados de las otras tareas más ordinarias. Juan Bautista Muñoz Sáenz de Navarrete, fiscal del consejo de Castilla, esposo de Juana Clara Muñoz de Otálora, distingue en su testamento entre «criados de escaleras arriba» $\mathrm{y}$ «criados de escaleras abajo», marcando la diferencia de estatus hasta en la cuantía de los legados ${ }^{17}$. Además de poseer un evidente papel funcional y utilitario,

\footnotetext{
13. BoudjaAva \& García, (2017): 2.

14. Fauve-Chamoux, (2009): 23.

15. DUBERT, (2017): 7.

16. BLANCO, (2016): 41-80.

17. Archivo Histórico de Protocolos Notariales de Madrid. T. 11432, fols. 432r/441v. Testamento de Juan Bautista Sáenz de Navarrete.
} 
los criados y sirvientes eran un elemento de ostentación, de honra del linaje y una garantía del buen funcionamiento de la casa y de eficiencia de la gestión de la hacienda familiar ${ }^{18}$. También servían como elemento publicitario del poderío de la familia y del linaje: no resulta extraño, por tanto, que todos aquellos que contaban con los recursos económicos suficientes trataran de adoptar los signos externos del caballero y rodearse del mayor número de criados posible ${ }^{19}$. El deseo de emulación de la corte de los Austrias convirtió la servidumbre en una característica intrínseca del modo de vida nobiliario: las grandes casas aristocráticas, a pesar del sempiterno endeudamiento, imitaron los usos y costumbres de los monarcas y constituyeron grandes cortes señoriales de boato personal ${ }^{20}$. Las estructuras de la servidumbre de la gran nobleza castellana, articuladas mediantes criados mayores y de librea, difería de la corte del monarca en su composición y número, pero poseía una misma función y un mismo sentido ${ }^{21}$.

Las élites urbanas y la pequeña nobleza adoptaron por mimetismo la servidumbre como medio público de ostentación, pero en su función pesaba más la utilidad práctica que la mera representación, especialmente en los medios rurales. Los artesanos y orfebres también sustentaban a una nutrida nómina de aprendices $\mathrm{y}$ de criados en sus casas y talleres ${ }^{22}$. Las grandes villas y ciudades eran un marco idóneo para representar el escenario del estatus y la apariencia, pero los criados eran más productivos en los medios rurales, donde la servidumbre estaba hondamente arraigada en el sistema laboral y familiar debido a la necesidad de mano de obra de labradores y ganaderos ${ }^{23}$.

Los grandes señores residían en las urbes, pero sus posesiones agrarias y sus ganados se encontraban en el medio rural. Las diferencias sociales en el campo no son tan pronunciadas en el plano económico y el servicio doméstico y la servidumbre puede camuflarse bajo relaciones muy diversas ${ }^{24}$. El reino de Murcia se caracterizaba por la concentración patrimonial en manos de unos pocos propietarios, debido principalmente al reducido grupo de terratenientes y al bajo número de colonos ${ }^{25}$. Los jornaleros, por tanto, eran imprescindibles y necesarios para laborar la tierra.

\section{LOS JORNALEROS}

Existían dos tipos de siervos: los criados libres y los esclavos. Los criados libres solían ser trabajadores esporádicos y asalariados o domésticos ${ }^{26}$. Los jornaleros eran muy numerosos y generalmente eran contratados para trabajar las tierras

18. SÁNCHEZ, 2018: 815-824

19. Chacón, (2006): 48.

20. CarrasCo, (1992): 203-209.

21. Carrasco, (1992): 204..

22. HidAlgo, (2020): 304-318.

23. TOVAR, (2020): 447

24. BlANCO, (2016): 48

25. Picazo Lemeunier (1984): 186.

26. SÁNCHEZ, (2012): 69. 
directamente explotadas por la familia, dedicándose a las actividades propias de la estación: siembra, recolección de los frutos, etc. Los ejemplos de este tipo de relación entre los jornaleros de las villas del entorno y los Muñoz de Otálora son muy abundantes: en enero de I613 Miguel de Reina y Juan de Gea, vecinos de Caravaca, se obligaron a cavar y a majar las viñas que Pedro Muñoz de Otálora, alférez mayor, tenía en la huerta de la villa ${ }^{27}$.

Francisco Musso Muñoz de Otálora, su hermano, seguirías las mismas pautas: en el mencionado año Diego López Higueras y Hernando Marín de Soto se obligaron a segar el trigo, la cebada y el centeno que tenía sembrado en los campos de Caravaca, cobrando por su trabajo el mismo jornal que el resto de peones ${ }^{28}$. Los jornaleros dependían ordinariamente de los grandes terratenientes de la villa y era frecuente que quedaran bajo su servicio durante años: En I6I5 Ginés López Higueras y su hijo se obligaron a cavar las viñas que tenía Pedro Muñoz de Otálora en la Huerta de la villa y a segar los panes del campo, recibiendo por su trabajo cuatro ducados por adelantado ${ }^{29}$.Todavía en I620 Diego López Higueras y Ginés López, su sobrino, se obligaron a ayudar en la siega a Juan Durán, aperador de Francisco Musso Muñoz de Otálora, su amo, cobrando de salario doce reales en dinero y cuatro fanegas de trigo a catorce reales ${ }^{30}$. La conclusión es que estas familias de peones y jornaleros permanecían durante generaciones al servicio de los grandes propietarios, como evidencia el caso de los Muñoz de Otálora.

Los peones agrícolas y jornaleros que trabajaban las tierras de los Muñoz de Otálora no siempre eran vecinos de la villa de Caravaca. En I6I2, por ejemplo, Francisco Giménez de Gea y Melchor López Yáñez, vecinos de la villa de Cehegín, se obligaron a segar los panes del mencionado Pedro Muñoz de Otálora ${ }^{31}$. Y en I6I5 Miguel Sánchez y Salvador González, vecinos de la cercana villa de Moratalla, se obligaron a segar los panes que Pedro Muñoz de Otálora, alférez mayor, tenían en el campo de la villa, cobrando por su trabajo veintiséis y treintaitrés reales respectivamente. Las coyunturas económicas desfavorables incidían de manera más directa en los sectores más pobres de la población. Los jornaleros en no pocas ocasiones eran asimilados a vagos, galopines y malentretenidos, gente ociosa cuyo destino solían ser las levas de los cuerpos de infantería o de la Real Armada ${ }^{32}$. El licenciado Juan de Mercado Lazcano, gobernador y justicia mayor de Caravaca, cumpliendo lo dispuesto en las pragmáticas reales sobre el castigo de la gente vagamunda y ociosa, mandó en i627 pregonar que «en días de travajo ninguna persona en lugar

27. AGM, Not. 7092, fols. 23r/v. Miguel de Reina y Juan de Gea se obligan a ayudar en el campo a Pedro Muñoz de Otálora.

28. AGM. Not. 7092, 25V/26r. Diego López Higueras y Hernando Marín de Soto se obligan a ayudar en la siega a Pedro Muñoz de Otálora.

29. AGM. Not. 7094, fols 26r/v. Ginés López Higueras y su hijo se obligan ayudar en la siega a Pedro Muñoz de Otálora.

30. AGM. Not. 7118, s. f. Diego López Higueras y Ginés López, su sobrino, se obligan a ayudar en la siega a Juan Durán, aperador de Francisco Musso Muñoz de Otálora.

31. AGM. Not. 7313, fols, 54r/v. Obligación para la siega de las heredades de Pedro Muñoz de Otálora.

32. HERNÁNDEZ Y QUIÑONERO (1985): 73-96. 
público ni secreto ponga juego de bolos ni argolla, so pena de dos años de destierro y vergüenza pública» ${ }^{3}$.

Las instrucciones del gobernador de la villa para evitar la confusión entre malentretenidos y auténticos menesterosos fueron precisas:

Ottrosí, por quanto es justo que los hombres que tienen salud para ganar con sus brazos y travaxos el sustento hordinario no se exerciten en officios ni entretenimientos que se pueden haçer por gente flazca y que no puede travaxar ${ }^{34}$

En el siglo XVIII la asociación entre menesterosos y trabajadores asalariados agrícolas es todavía más clara. La subida salarial de los peones fue insuficiente y a partir de la segunda mitad del siglo se produce un progresivo deterioro de sus condiciones de vida y afloran documentos oficiales que exponen su deplorable situación socioeconómica motivada por la falta de trabajo y de recursos ${ }^{35}$. En la centuria precedente, a pesar de la profunda crisis económica, había suficiente trabajo para los peones agrarios. El gobernador de Caravaca prohibió taxativamente que las personas con salud corporal, a excepción de los destiladores, vendiesen por las calles de la villa aguardiente y conservas. También dispuso que tanto los vecinos de la villa como los forasteros que no tuviesen hacienda buscasen trabajo en el campo o en la ganadería:

que todas las personas vecinos y forasteros estantes en ella que no tuvieren hacienda raíz, trato o granjería asentada y conoçida con que se pueda sustentar a sí y su familia asienten a officio o con amo para travaxar en la labor del campo, guardar ganado u otro ministerio o travaxen cada día a jornal con que puedan sustentarse y los que tubieren officio o ganaren con sus brazos de comer todos los días de travaxo asistán a el sin andarse ociossos y vagamundos por la villa ${ }^{36}$.

Los horarios y los salarios de los jornaleros estaban sometidos al arbitrio de los amos, aunque en alguna ocasión el concejo trato de regularlos para evitar las frecuentes situaciones abusivas. En I603 la villa dictó unas ordenanzas regulando los salarios de los jornaleros y menestrales. Los trabajadores agrícolas cobrarían por su trabajo un real y medio por las faenas realizadas entre agosto y febrero y dos reales para las tareas desarrolladas entre marzo y junio, quedando los amos en ambos casos obligados a proporcionarles la preceptiva comida, variando asimismo los horarios laborales dependiendo de la estación del año ${ }^{37}$. En I627 los jornales fueron de nuevo regulados por el arancel de precios y salarios: los encargados de cortar la uva, por ejemplo, cobrarían un real y medio, los cavadores en la huerta y en el campo entre uno y dos reales y medio, dependiendo de los meses, y los segadores tres reales y medio, quedando en este caso los amos asimismo obligados a proporcionarles el

33. AGM. Not. 7266 , fols. 383 r/46or. Arancel de precios y salarios de la villa de Caravaca.

4. AGM. Not. 7266 , fols. 383 r/46or. Arancel de precios y salarios de la villa de Caravaca.

35. GonZÁLEZ, (2011): 237-270.

36. AGM. Not. 7266 , fols. 383 r/46or. Arancel de precios y salarios de la villa de Caravaca.

37. FERNÁNDEZ, (2015): 85 
sustento diario ${ }^{38}$. En la mayor parte de las escrituras de obligación para trabajar las tierras de los Muñoz de Otálora se precisa que deben cobrar el mismo salario que el resto de peones, quedando los contratos restringidos al tiempo que duraran las tareas agrícolas. En ocasiones recibían parte del salario por adelantado o combinaban el dinero con el pago en especie.

\section{LOS ARRIEROS}

Los contratos de los Muñoz de Otálora con los numerosos arrieros de la villa también eran frecuentes, especialmente para el acarreo de las numerosas lanas de sus ganados y para la distribución y posterior comercialización de sus excedentes agrarios, aunque casi siempre se hacían de palabra, sin necesidad de realizar costosas escrituras ante notario. Además, la familia disponía de una importante cabaña de burros, bueyes y carros para transportar el grano y demás productos granjeados en sus tierras. Los productos agrarios de la familia, especialmente el trigo, la cebada y el centeno, se distribuían en el parador del campo y se almacenaban en los diversos graneros de las casas y cortijos de la heredad de Tarragoya. Los Muñoz de Otálora mantenían prácticamente una economía autosuficiente: poseían lavaderos de lanas, tendederos, molinos, batanes y otro tipo de industrias. Las lanas las sacaban mediante arrieros a través de Cuenca o Burgos o a través de los puertos de Cartagena y Alicante.

La figura del arriero o carretero, por tanto, resultaba clave en los procesos económicos de la familia. Lo arrieros solían permanecer durante años al servicio de la familia, dedicándose prácticamente en exclusiva a transportar sus lanas y pieles, sus productos agrarios y las maderas de sus explotaciones forestales. Este tipo de trabajadores especializados no formaban parte de los agregados domésticos y normalmente residían en sus propios hogares: Pedro Martínez, arriero de Pedro Muñoz Briceño, vivía en la calle de Pedro Pérez con su propia familia39. Lázaro Ruiz estuvo durante años al servicio de Pedro Muñoz Briceño de Otálora, alférez mayor de la villa, recibiendo un trato acorde a la importancia económica de la labor desarrollada. De hecho, en su testamento no dudaba en afirmar que el susodicho no le que quitaría nada de su salario, sino que le favorecería «con más de los que me debiere» ${ }^{40}$.Los Muñoz de Otálora también disponían de personal dedicado exclusivamente a la fabricación y reparación de los carros. Francisco Martínez, oficial de hacer carros, estuvo al servicio de la familia al menos durante ocho años, viviendo «en un parador de carros del dicho don Pedro Muñoz Briceño tres años y después, cerca del dicho parador, otros cinco años» ${ }^{4 \mathrm{I}}$.

\footnotetext{
38. AGM. Not. 7266, fols. 383r/46or. Arancel de precios y salarios de la villa de Caravaca.

39. ARChG. Caja 9930, pieza 8. s. f. Declaración de Pedro Martínez, arriero.

40. AGM. Not. 7089, fols. 593v/595r. Testamento de Lázaro Ruiz, vecino de Caravaca.

41. ARChG. Caja 9930, pieza 8.
} 


\section{ADMINISTRADORES, MAYORALES Y PASTORES}

Otro importante grupo de criados de la familia Muñoz de Otálora lo componían los mayorales y pastores que ordinariamente criaban y cuidaban de sus cabañas y hatos de ganados. A lo largo del siglo XVII los Muñoz de Otálora continuarían con la crianza de ganado ovino y bovino, aunque observamos en casi todas las líneas del linaje una creciente importancia de la cría del ganado equino y caprino. El mayoral, persona de confianza de la familia, era el principal de los pastores y el encargado de cuidar de la buena crianza y gobierno de los ganados. En el caso de los Muñoz de Otálora parece que también ejercían algunas funciones de capataces y de administradores de la hacienda familiar ${ }^{42}$. También eran los encargados de pagar los salarios de los pastores y de gestionar, junto a los apoderados, los arrendamientos de las dehesas para el pasto de los ganados ${ }^{43}$. Francisco Burruezo ejercería de mayoral del licenciado Pedro Muñoz de Otálora, alférez mayor de la villa, y Francisco Rubio Sánchez, vecino de Baza, estuvo al servicio del susodicho durante un año, quedando posteriormente al cuidado de los ganados que Pedro Muñoz Briceño, su hijo, tenía en la hacienda de Tarragoya, empleo que desempeñaría durante nueve años ${ }^{44}$. Alonso Fernández Montoya también ejerció de mayoral de Pedro Muñoz Briceño, pasando en I637 a servir a Pedro Musso Muñoz.

No era raro que los mayorales permanecieran durante varias generaciones al servicio de la familia: Domingo Martínez, por ejemplo, ejerció de mayoral de los ganados de Pedro Muñoz de Otálora, heredero de Pedro Muñoz Briceño, quedando a servicio de Juan Bautista Muñoz de Navarrete, su yerno, a partir del año I654. Otro tanto observamos con Juan de la Fuente, mayoral de Juana Clara Muñoz de Otálora y de Juan Bautista Muñoz Sáenz de Navarrete Uribe Yarza, su nieto. La fidelidad y los servicios de los mayorales y criados eran recompensados por los miembros de la familia de diversas formas y con bastante frecuencia: en I685 Juan Clara Muñoz de Otálora legaría por su testamento diez ducados al mencionado Juan de la Fuente ${ }^{45}$, idéntica cantidad a la legada por su nieto en $1692^{46}$. Las relaciones de los Muñoces con sus pastores, no obstante, parece que fueron más volubles y menos duraderas

La relación contractual de los Muñoz de Otálora con los pastores se realizaba ordinariamente de palabra mediante un contrato verbal que se revocaba cuando alguna de las partes decidía ponerle fin, ${ }^{47}$ aunque contamos con algunas cartas de soldada. En I6or Bartolomé Sánchez y Juan de Alarcón, su hijo, se pusieron a servicio de soldada con Pedro Muñoz de Otálora, alférez mayor, para servir de pastores de su ganado durante un año, cobrando cada uno I8 ducados» ${ }^{4}$. Las cartas de soldada casi siempre registran las mismas condiciones contractuales: en I603 Miguel López, pastor, se puso a servicio de soldada del mencionado Pedro Muñoz de Otálora para

2. ARChG. Caja 9930, pieza 8. s. f.

43. AGM. Not. 7308, fols. 76or/765r.Testamento de Pedro Muñoz de Otálora, alférez mayor de la villa de Caravaca.

44. ARChG. Caja 9930, pieza 8. s. f.

45. AGM. Not.7189, fols. 183r/189r.Testamento por poderes de Juana Clara Muñoz de Otálora.

46. AGM. Not. 7399, fols. 8r/ılv. Testamento y codicilo de Juan Bautista Muñoz Sáenz de Navarrete.

47. DUBERT, (2005): 10.

48. AGM. Not. 7118, fols. 13r/v. Escritura de soldada de Bartolomé Sánchez, pastor, y de Juan de Alarcón, su hijo. 
guardar sus cabras, cobrando igualmente i 8 ducados de salario ${ }^{49}$. Era frecuente que los pastores incluyeran sus propias cabezas de ganado en los hatos de sus amos para aprovechar los pastos de las dehesas y reducir los costes de la crianza: Miguel López impuso como condición llevar las cincuenta cabras que poseía en el rebaño de Pedro Muñoz de Otálora. Los criados domésticos de la familia también solían incorporar sus hatos a los rebaños de sus amos: Alonso Martínez de Andrada, por ejemplo, mayordomo de Pedro Muñoz Briceño, llevaba sus novillos, sus vacas, sus cabras y sus cerdos con los ganados de su señor ${ }^{50}$.

La familia Muñoz de Otálora también aprovechó la experiencia de los pastores navarros para garantizar la buena crianza de sus ganados. Pedro Muñoz de Otálora, alférez mayor de la villa, tuvo durante algunos años empleado a Juan Navarro Monturries, pagando por sus servicios veinte ducados anuales. ${ }^{5 \mathrm{I}}$ Francisco Musso Muñoz de Otálora también contó con los servicios de Fernando Navarro, pastor, al cual adeudaba cierta cantidad de reales de su salario. El arancel de I627 reguló el salario de los pastores de la villa, diferenciando entre mayorales, manaderos, hateros y zagales. Los mayorales debían cobrar veinticuatro ducados anuales y además el amo debía proporcionarle la comida y el calzado de alpargates; los manaderos cobrarían veinte ducados, quedando por cuenta del amo igualmente la comida y el calzado; los hateros recibirían de salario dieciséis ducados anuales por la crianza de los machos y catorce por el cuidado de las cabras, recibiendo gratuitamente la comida y los alpargates; finalmente el amo debía pagar a los zagales doce ducados anuales, así como proporcionarles los alpargates y la comida. También se les permitía llevar sus ganados con los del amo, pagando, como era costumbre, dos reales por cada cabeza que superare la cuantía estipulada: los mayorales podrían llevar cincuenta cabezas de ganado libres de toda costa; los manaderos veinte, los hateros dieciséis y los zagales doce ${ }^{52}$.

Los pastores o manaderos iban acompañados frecuentemente de zagales que ayudaban a cuidar del rebaño: Juan Marín de Veas, por ejemplo, ejerció de zagal de Monturries. Los autores del siglo XIX proporcionan información sobre el personal encargado de cuidar de los rebaños: para una manada iıoo ovejas, según Manuel del Río, era preciso tener un rabadán, un compañero, un ayudador, un sobrado y un zagal ${ }^{53}$.También encontramos lazos de parentesco entre los manaderos que cuidaban los diferentes rebaños: Monturries era cuñado de Miguel de la Fuente, criado de los Muñoz de Otálora. Las relaciones entre los Muñoz de Otálora y sus manaderos y pastores a veces eran cercanas: Francisco Musso Muñoz de Otálora, por ejemplo, pagó el testamento de Francisco Ramal, pastor.

A los sectores sociales más desfavorecidos no les quedaba otro remedio que poner a sus hijos a servicio de soldada con los oligarcas o con los artesanos y orfebres de la villa. La entrada al servicio se producía a edades tempranas, apenas llegaba la

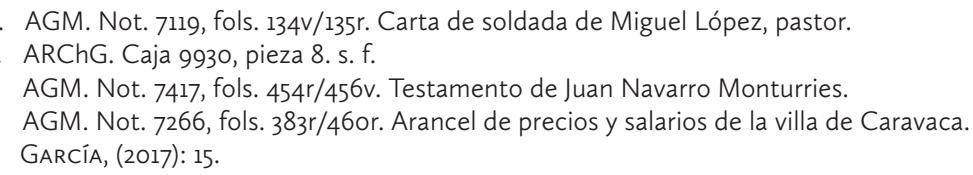


adolescencia ${ }^{54}$. A veces incluso antes: en I627 el gobernador de la villa de Caravaca dispuso que los niños de diez años arriba se pusieran a servir con amo en el campo o en la ganadería:

ay alguna gente que cuydan poco de endereçar sus hixos al trabaxo, antes como ellos son holgazanes, enseñan lo mismo a sus hixos por ser natural seguir los hixos las condiciones de los padres. Por tanto, mando se pregone que todas las personas de la calidad referida en el auto antecedente, si tuvieren hixos de diez años arriba, los pongan a officio o a serbir con amo para que se enseñen a el travaxo del campo, cultivando la tierra o guardando ganado o exerçitándose en otro exerçiçio corporal y no les consientan andar holgaçenes por la villa ni salir a la guerta a hacer daños ${ }^{55}$.

En la Galicia interior, según datos proporcionado por Dubert, las mujeres asentaban el oficio de criadas en torno a los nueve o diez años, edades poco más tempranas que las registradas en Caravaca, mientras que en el mundo rural de países como Inglaterra la entrada de las mujeres en el servicio era mucho más tardía. Esta disparidad encuentra su explicación en el estrato social al que pertenecían las criadas gallegas: los sectores sociales más pobres del campesinado ${ }^{56}$. Algunos estudios recientes inciden en el rol de la domesticidad, y más propiamente en la repercusión del trabajo asalariado, en las economías de las familias de origen de estos niños, los cuales, en no pocos casos, solían trabajar fuera del hogar ${ }^{57}$. Otros trabajos abundan en lo roles desempeñados por los mozos en las grandes explotaciones mediterráneas que precisaban del trabajo asalariado ${ }^{58}$.

Los contactos socio-culturales de los criados con sus señores permitían articular estrategias de promoción social individual, tanto desde el punto de vista de la propia carrera profesional como desde la perspectiva de las alianzas matrimoniales $^{59}$. El ascenso en la jerarquía de servicio permitía incluso que los criados llegaran a amasar pequeñas fortunas gracias al favor y a la participación en los negocios de los señores. Un ejemplo relevante de promoción social en el ámbito del servicio lo encontramos en el caso de Alonso Martínez Andrada: nació en Lorca en el seno de una familia de condición muy humilde y en torno al año I6ı2 entró a servicio de Pedro Muñoz de Otálora, alférez mayor de Caravaca, cuando «era muchacho de hasta doce o catorce años y muy pobre». Comenzó en un principio como recadero y haciendo mandados para la familia, aunque muy pronto entró a trabajar en la hacienda del campo:

\footnotetext{
54. DUBERT, (2005): $27-48$.

55. AGM. Not. 7266, fols. 383r/46or. Arancel de precios y salarios de la villa de Caravaca.

56. DUBERT, (2017): 6.

57. BOUdJAABA \& HERMENT (2017): 7.

58. JOVER, PuJADAS \& SUAU (2017): 2

59. Fauve-Chamoux, (2009): 22.
} 
luego le enviaron al cortijo de Tarragoya, donde estuvo muchos días guardando el ganado de cerda y siendo pastor de ganado cabrío, hasta que por muerte del dicho don Pedro Muñoz de Otálora quedó en servicio del dicho don Pedro Muñoz Briceño ${ }^{60}$.

Consiguió ganarse el favor de Pedro Muñoz de Otálora, convirtiéndose tempranamente en mayoral y administrador de su hijo, a cuyo servicio estuvo más de 22 años, acudiendo a los heredamientos del campo, asistiendo al cuidado de los numerosos ganados y cobrando las rentas de la hacienda. Pedro Muñoz Briceño premiaría la fidelidad de su mayordomo haciéndole diversos regalos, entre ellos una casa y una herrería situadas junto al parador de los carros. Ordinariamente también pagaba la comida y las ropas de su mayordomo:

andaba vestido con mucha autoridad, trayendo calzón de terciopelo, media de seda, manga de tirela, ropilla y herreruelo de paño fino y vestidos de color muy buenos, que importaría en cada un año más de cinquenta ducados ${ }^{61}$

Aunque al parecer no cobraba salario alguno por su trabajo, reunió el dinero suficiente para adquirir algunas propiedades en la huerta de la villa de Caravaca y en la ciudad de Lorca:

estando en servicio del dicho don Pedro Muñoz Briceño compró un bancal a los herederos de Maldonado, vecinos de la villa, y que compró o tenía propiedades en Lorca y que compró un cortijo que hoy tiene Bernabé Martínez, su hermano ${ }^{62}$.

Numerosas personas de la villa de Caravaca, influenciadas por Pedro Muñoz Otálora, heredero de Pedro Muñoz Briceño, no dudaban en sugerir que Alonso Martínez Andrada había conseguido amasar una pequeña fortuna aprovechándose y hurtando algunos dineros y joyas de la hacienda de su amo. Lo cierto es que Martínez Andrada no tenía asignado un salario fijo y periódico, pero en el día a día recibía dineros de su amo por los trabajos de administración y cobranza de las rentas de los censos y de los juros familiares. Ordinariamente vigilaba que los pastores cuidasen bien de los ganados, cobraba las rentas de los arrendamientos, ordenaba las cosas de la casa, vendía los excedentes agrarios y pagaba los salarios del resto de criados. Igualmente paseaba ordinariamente por la villa junto a su amo. La relación entre uno y otro era tan estrecha que hasta el propio Pedro Muñoz Briceño intentó casarlo «con una mujer de importancia», ofreciéndole dos mil ducados en dote y «otros dos mil para que pudiera pasarlo bien en remuneración de lo que le había servido». Finalmente se quedó solo en el gobierno de la casa y de la hacienda:

disponía lo que en ellas se había de hacer y se apoderó de todos los bienes y llaves de la casa y aposentos, escritorios, arcas y baúles de la casa ${ }^{63}$

\footnotetext{
6o. ARChG. Caja 9930, pieza 8. s. fol.

61. ARChG. Caja 9930, pieza 8. s. fol.

62. ARChG. Caja 9930, pieza 8. s. fol.

63. ARChG. Caja 9930, pieza 8. s. fol.
} 
Aunque, al parecer, sabía leer poco y mal y necesitaba una persona que llevara las cuentas de la administración, Pedro Muñoz Briceño le designó como albacea testamentario y dispuso que quedara en servicio de Pedro Muñoz de Otálora, su primo, heredero de los vínculos y mayorazgos de la familia ${ }^{64}$. No obstante, supuestas ocultaciones y hurtos de joyas y bienes le granjearon su enemistad y la cárcel ${ }^{65}$ y finalmente ocasionaron algunos pleitos que se sustanciaron en la chancillería de Granada ${ }^{66}$.

Los criados domésticos de los Muñoz de Otálora siempre fueron muy numerosos, tanto en el siglo XVI como en las centurias siguientes, aunque evidentemente no podemos precisar cifras concretas. Algunos mayorazgos de la familia, como Pedro Muñoz Briceño, «caballero muy moderado en el gasto de su persona, familia y criados» ${ }^{67}$, mantuvieron a su servicio un relativamente reducido número de sirvientes, aunque en líneas generales la mayor parte de los Muñoz de Otálora cumplieron con los preceptos culturales del Antiguo Régimen: el ethos nobiliario contribuyó a generar la asociación simbólica entre el número de criados disponible y la posición social que se ostentaba o se pretendía representar, propiciando que su posesión se interpretara como un signo manifiesto de estatus social ${ }^{68}$. Francisco Musso Muñoz de Otálora, regidor, declara en su testamento que tuvo en su casa «munchos criados y renteros» ${ }^{69}$. Los criados domésticos en ocasiones eran agasajados en fiestas o días señalados. La carta de soldada de Martín Guerrero, hijo de Isabel de Moya, viuda de Juan Guerrero, especifica que debía cobrar I4 ducados anuales y una carretada de leña para el día de Navidad $^{70}$.

Autoras como Faveux-Chamoux ponen de relieve la importancia del servicio de los jóvenes y la repartición desigual de los roles domésticos asociados al género ${ }^{71}$. Las mujeres eran las responsables del cuidado del hogar y de la asistencia de los miembros de la familia ${ }^{72}$. Las escrituras de soldada otorgadas por los Muñoz de Otálora no especifican con claridad las diversas tareas que las criadas debían asumir, aunque parece que existía una cierta especialización. Las criadas eran las encargadas de preparar los alimentos, la mantelería y la cubertería, así como de la lavar ropa y de asistir a los señores y a las doncellas de la casa. También ejercían tareas cotidianas como barrer, hacer las camas, fregar o guisar ${ }^{73}$. Igualmente eran las encargadas de coser y planchar la ropa, del bordado, de la preparación de conservas y de acompañar a sus señores en los actos sociales ${ }^{74}$. Asimismo, eran las encargadas de cocer el pan y de recoger el agua del pilar y de lavar la ropa. De hecho, las ordenanzas de la villa de Caravaca prohibían expresamente que los hombres se parasen a mirar a las mujeres que hacían sus trabajos en los lavadores públicos.

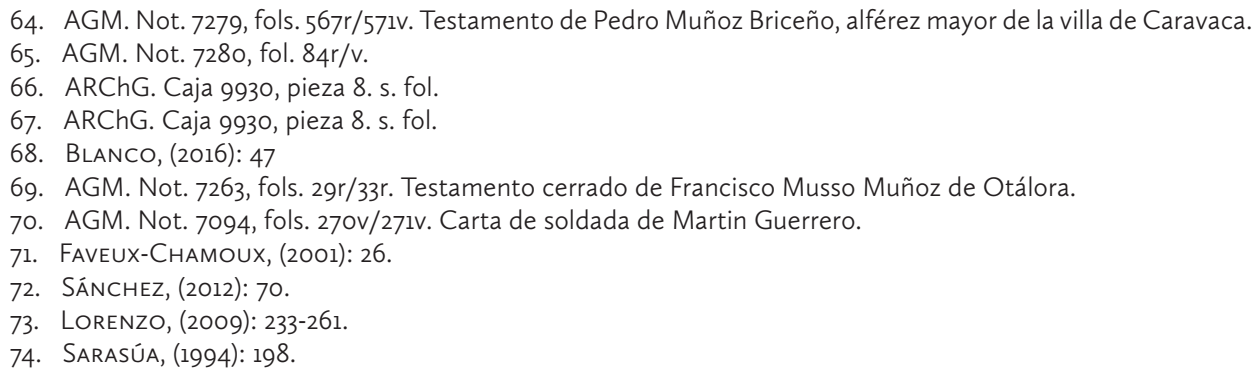


El arancel de precios y salarios elaborado por la justicia de la villa en $\mathrm{I} 627$ distingue entre dos tipos de criadas: «la muger hecha» y las muchachas. Las primeras debían cobrar un salario anual de seis ducados y el amo debía proporcionarles tocas y zapatos; las muchachas cobrarían treintaiséis reales, zapatos y tocas ${ }^{75}$. Lo más frecuente era que entraran a servir con doce o catorce años y que los contratos estipulasen una duración de seis u ocho años. Francisco Tomás Melgares, curador de Isabel de la Peña, puso a su menor en servicio de Pedro Muñoz de Otálora por 6 años, con un salario anual de 5 ducados. Pedro Muñoz debía darle de comer, de vestir, así como proporcionarle el calzado necesario, darle vida honesta y razonable y prestarle asistencia médica en caso de enfermedad ${ }^{76}$.

En el periodo moderno era ciertamente frecuente que los curadores pusieran a sus menores a servicio de soldada en casas de familias poderosas o de aprendices en talleres de artesanos. El licenciado Jorge Pérez Baladejo puso en I625 a Marina Benítez, su menor, a servir con Catalina Muñoz de Otálora, viuda de Antonio Briceño, señor de Gramedo y Molezuelas, por espacio de ocho años ${ }^{77}$. La señora se obligaba a pagar un salario de tres ducados anuales durante los cuatro primeros años y cuatro ducados durante los restantes cuatro años del contrato. Además, se comprometía a darle de comer y de beber, así como vestidos y calzados para su uso cotidiano. Igualmente se comprometía a darle «vida onesta y raçonable, cama en que duerma y curalla en sus enfermedades» durante todo el tiempo que estuviese a su servicio.

En algunas ocasiones las criadas percibieron algunos dineros de su salario por adelantado. En i628 Francisca Rodríguez, viuda de Francisco García, recibió ocho ducados por adelantado de la soldada de María López, su hija, a la cual había puesto a servicio de Pedro Muñoz de Otálora por tiempo de 8 años con un salario total de 29 ducados: tres ducados los tres primeros años y cuatro ducados los cinco restantes ${ }^{78}$. Los salarios eran, en cualquier caso, muy variables y dependían de factores como la edad o el estatus de los señores. En la Galicia interior, por ejemplo, las soldadas también variaban en función de la zona: en Santa Mariña de Xuño los criados de las élites campesinas recibían una media de iI4 reales anuales, mientras que en San Martiño de Ermedelo la soldada se situaba en torno a los I24 reales $^{79}$.

En general, las mozas de soldada, tal y como ilustra el ejemplo de los Muñoz de Otálora, solían ser huérfanas o hijas de viudas, personas, en definitiva, necesitadas de recursos económicos. En Italia sucedía algo parecido: los sirvientes generalmente eran de clases humildes o mujeres marginadas sin familia ${ }^{80}$. Según De Molin, la mayor parte de los sirvientes eran huérfanos, niños abandonados, mujeres deshonradas y viudas sin familia ${ }^{81}$. En España, a través de estos contratos de soldada, las familias necesitadas se quitaban una boca que alimentar, vestir y calzar y las

5. AGM. Not. 7266, fols. 383 r/46or. Arancel de precios y salarios de la villa de Caravaca.

76. AGM. Not. 7273 , fols. $471 \mathrm{r} / 472$. Servicio de soldada de Isabel de la Peña.

77. AGM. Not. 7264, fols. 713r/174r. Servicio de soldada de Marina Benítez.

78. AGM. Not. 7344, fol. 73r/v. Servicio de soldada de María López.

79. DUBERT (2017): 9

80. SARTI, (2007): 23.

81. DA MOLIN, (2007): 521-522. 
doncellas generaban ahorros para su dote o para contribuir a la economía familiar. La fórmula contractual, exenta de gastos y de larga duración, era ideal para que las doncellas ahorrasen todo su salario y pudiesen generar una dote lo suficientemente atractiva para contraer matrimonio. Este proceso ya fue observado en ciudades como Castellón $^{82}$. En algunas ocasiones las dotes ofrecidas por los amos respondían a una supuesta compensación a la actitud sumisa de las doncellas ${ }^{83}$. Si bien, otras veces las dotes eran entregadas por los propios señores en remuneración a los servicios prestados. Este es el caso de Isabel de Frías, viuda de Fabián Muñoz, ama de cría de Inés Muñoz de Bohorques. Pedro Muñoz de Otálora, alférez mayor de la villa, se obligó a entregarle una dote de II4I28 maravedís «en pago del servicio y crianza de doña Inés Muñoz de Bohorques», su hija, ${ }^{84}$ para que pudiera contraer matrimonio con Pedro López, su criado. En ciertas regiones de España y de Italia, contrariamente a lo que sucedía en Francia, el matrimonio y el servicio doméstico no eran incompatibles ${ }^{85}$.

\section{LAS AMAS DE SERVICIO Y LAS AMAS DE LECHE}

El estatus y la jerarquía de las criadas obedecían tanto al tipo de tareas desarrolladas en la casa y en la familia como a la ascendencia y a la capacidad de influencia sobre los amos. Las amas, mantenían unas estrechas relaciones afectivas con sus señores, se encargaban de administrar el servicio de la casa y cumplían con la función de gestionar el personal que trabajaba para la familia. Sus salarios eran de mayor cuantía que los que recibían el resto de criadas: Gonzalo Muñoz, por ejemplo, declara en su testamento que entregaba de salario anual a María Barba, su ama, doce ducados ${ }^{86}$.

Gracias a la cercanía que mantenían con sus amos eran apreciadas y reputadas en la comunidad: ejercían ordinariamente de madrinas, tanto en los bautizos de los numerosos vecinos de la villa de Caravaca como en los de los propios criados y esclavos de la familia. El ejemplo que nos proporciona María García, ama de servicio de Gonzalo Muñoz, regidor, ilustra la proyección social de los criados más cercanos a la familia: ejerció de madrina en 67 ocasiones entre 1605 y I620, cifra que representa poco más del 1,5\% del total de bautizos para ese periodo. María García y su marido eran los criados predilectos de Gonzalo Muñoz, los que le habían servido «con más amor y voluntad» durante más de veinticinco años. Las amas ejercían de intermediaras para crear lazos de dependencia con otros vecinos de la villa y también solían ejercer de madrinas en los bautizos de los esclavos de la familia: Elvira Gómez, ama del licenciado Pedro Muñoz, amadrinaría en 1580 a Francisco, a Gaspar y a Pedro, esclavos adultos del mencionado licenciado.

82. GARRIDO, (1996):105-116

83. Aragón, (1989): 403-424

84. AGM. Not. 7118, fols. 325V/327r. Dote de Isabel de Frías.

85. Fauve-Chamoux, (2009): 19.

86. AGM. Not. 7350, fols. 86r/116v. Testamento de Gonzalo Muñoz. 
Era normal que permanecieran durante años al servicio de la familia, especialmente si también habían ejercido de nodrizas: Constanza Martínez amamantó y crió a Pedro Muñoz Briceño, a cuyo servició estuvo durante más de treinta y cuatro años. Constanza gestionaba y dirigía la casa de su señor junto al mayordomo. La lactancia materna era considerada como un trabajo servil, circunstancia que explica que las mujeres que disfrutaban de cierto estatus contrataran a esto tipos de mujeres para la crianza de sus hijos ${ }^{87}$. La lactancia generaba grandes oportunidades de trabajo para las mujeres, propiciando incluso grandes desplazamientos, como evidencia el caso de las nodrizas pasiegas. En Madrid, en el siglo XVIII, la lactancia era una actividad asalariada que dio origen a un mercado de nodrizas en el que tenían cabida tanto las campesinas de los alrededores que criaban a los niños en sus casas como las asalariadas de las inclusas o las nodrizas que formaban parte del propio servicio doméstico ${ }^{88}$. Este último parece ser el caso de Constanza Martínez y los Muñoz de Otálora. No obstante, algunos tratadistas como Hecquet, entendían que la condición nobiliaria no era impedimento para dejar de lado las obligaciones maternas. La defensa de la lactancia materna se basaba en ciertas reivindicaciones de fundamentos naturales, religiosos, antropológicos y médicos, etc. ${ }^{89}$

La fidelidad y los años de servicio casi siempre eran reconocidos y premiados: Pedro Muñoz Briceño dispuso por su testamento que su ama permaneciera a servicio de su heredero o bien recibiera cuatrocientos ducados como compensación. Las amas eran ciertamente apreciadas por la familia. Ana López, ama de leche de Teresa Muñoz de Velasco, hija del capitán Gonzalo Muñoz Girón y de Juana de Velasco, en el año I6o6 cobraba dieciséis reales mensuales por la lactancia:

\begin{abstract}
mando se le den a Ana López, ama de doña Teresa Muñoz de Belasco, mi hija, lo que paresçiese se le debe del tienpo que a dado leche a la dicha mi hija y diere hasta que la dexe destetada, e ago qüenta con ella e reçiviendo en quenta lo que la susodicha pareçiere aver reçivido que se le da cada mes diez e seis reales y demás desto le mando el manto que lleba puesto, que es mío, y una saya de bureles que es fino, que era de doña Juana de Belasco, mi muger e madre de la dicha doña Teresa, que esté en el cielo, esto si acavare de dalle leche, porque si la desanpara antes tan sólamente se le pague lo que se le debiere, e no le mando la saya e manto9\%.
\end{abstract}

Las mandas, legados y donaciones testamentarias en ocasiones proyectan situaciones de reconocimiento por el trabajo realizado o sentimientos afectivos del amo con respecto al siervo, pero la realidad social de las criadas escondía otra cara menos amable: las violaciones, forzamientos y estupros. La explotación sexual de las criadas fue una constante en la España del periodo moderno, si bien las protestas y los pleitos en no pocas ocasiones se saldaban con una reparación económica que ponía remedio al agravio moral, a los costes de los pleitos o a los gastos derivados

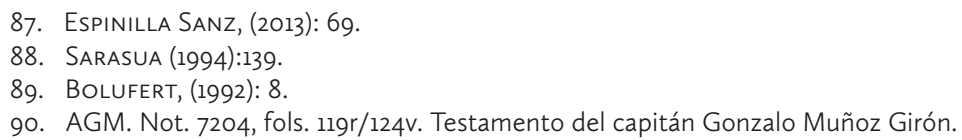


de embarazos no deseados ${ }^{91}$. Los Muñoz de Otálora no fueron una excepción: Pedro Muñoz de Otálora, alférez mayor de la villa, denunciaba que Pedro Jacinto Muñoz de Otálora, su primo, había intentado besar y forzar a una joven doncella que recogió en la ciudad de Lorca. Al parecer, se acostó en su alcoba y llamó a la joven criada con el pretexto de limpiar la habitación, aprovechando ese momento para hacerle proposiciones deshonestas e intentar mantener relaciones sexuales ${ }^{92}$. Los Muñoz de Otálora también tuvieron hijos con sus criadas, aunque desconocemos la naturaleza de las relaciones. El licenciado Pedro Muñoz, alférez mayor de Caravaca, reconoció a un hijo natural nacido de un acceso carnal con Catalina Rodríguez, su criada. En su testamento le mandó cincuenta ducados para "ayuda a casarse» ${ }^{93}$, tal vez como reparación de la deshonra que suponía la perdida de la virginidad y el embarazo sin haber contraído matrimonio.

Los Muñoz de Otálora también prestaban ayuda y cobertura material a los sirvientes de sus casas, especialmente cuando se encontraban en momentos críticos o dificultosos. Sancho Muñoz de Otálora, canónigo de la catedral de Toledo, dispuso por su testamento que sus albaceas asistieran a su costa a María Gómez, su criada, hasta que se finalizara el pleito que tenía pendiente, entregándole, además, otros ciento y cincuenta reales una vez que se hubiese finalizado ${ }^{94}$. El estamento eclesiástico destaca a lo largo del Antiguo Régimen como el grupo social con mayor demanda de personal asalariado a su servicio, actuando además como intermediador en la inserción de los criados en casas de la nobleza ${ }^{95}$. En Galicia, por ejemplo, el 75,2\% de los hogares encabezados por un clérigo (el 2,1\% del total) disponía de sirvientes, resultando ser mujeres en el 58,7\% de los $\operatorname{casos}^{96}$. En Murcia, las dignidades y los canónicos disfrutaban de una media de 5,2 sirvientes por hogar, resultando ser varones el 3\% y el 2,2\% mujeres. La alta presencia de sirvientes en los hogares de eclesiásticos responde a razones de tipo social y práctico: los clérigos no disponían de pareja que hiciera las tareas domésticas y por tanto necesitaban de personas que las realizaran, aunque en ocasiones la contratación de personal asalariado podrían ser fórmulas para ejercer la caridad con los más desfavorecidos, sin olvidar que además suponían una mano de obra barata ${ }^{97}$.

El licenciado Sancho Muñoz de Otálora, canónigo de la Catedral de Toledo, disponía de una nutrida nómina de criados a su servicio, tal y como evidencia su testamento: al menos, un administrador de la hacienda, un administrador de los vestuarios de la canonjía, dos pajes, un criado y dos criadas. El número de asalariados domésticos, no obstante, debía ser mayor, pues en el testamento tan solo menciona a aquellos a los que legó algún dinero.

91. Lorenzo Pinar, F. J. (2009): 280.

92. AHN. CONSEJOS, 25857, Exp. 5. Relación sobre la conducta de Pedro Jacinto Muñoz de Otálora.

93. AGM. Not. 7055, fols 331r/341r. Testamento del licenciado Pedro Muñoz.

94. AHPTO. Prot. 16399, fols 450r/453v. Testamento de Sancho Muñoz de Otálora, canónigo de la catedral de Toledo.

95. Sarasúa, (1994): 64.

96. DUBERT. (2005): 20

97. IRIGOYEN, (2010): 307-327. 


\section{LOS ESCLAVOS DE LA FAMILIA MUÑOZ DE OTÁLORA}

El otro gran grupo de sirvientes de la familia los constituían las personas sometidas a esclavitud, especialmente berberiscos y moriscos, pero también negros africanos y mulatos, aunque en menor medida. La esclavitud moderna resurge en Europa ligada estrechamente a la producción de la caña de azúcar irrigada que necesitaba de una abundante mano de $\mathrm{obra}^{98}$. Desde hace algunas décadas se tiende a considerar que los esclavos, más que un signo de ostentación, eran trabajadores rentables ${ }^{99}$. En Caravaca las principales familias esclavistas eran los Muñoces y los Mora. Parece que los Muñoz de Otálora no participaron activamente en la trata de esclavos, al menos en los grandes circuitos y mercados internacionales, aunque en la documentación rastreamos con relativa frecuencia las compraventas de siervos.

En ocasiones las ventas quedaban dentro de la propia familia: en I627 Pedro Muñoz de Otálora traspasó una esclava a Francisco Musso Muñoz de Otálora ${ }^{\text {100 }}$. Los Muñoz de Otálora establecidos en la corte también vendieron algunos de sus esclavos en la villa de Caravaca: en I633 Pedro Jacinto Muñoz de Otálora, caballerizo de la reina y caballero de la orden de Santiago, otorgó carta de venta de una esclava en favor de Jacome de Bracamonte, genovés, administrador de la encomienda ${ }^{\text {ror }}$. Otras veces las ventas eran forzadas para satisfacer los pagos pecuniarios de faltas y delitos contra la hacienda real o contra particulares: Francisco Gallego, administrador de la hacienda embargada de Francisco Musso Muñoz de Otálora, otorgó poder a Juan Musso Muñoz para vender a un esclavo berberisco llamado Ginés con el propósito de satisfacer lo estipulado en los perdones que se hicieron de las muertes de Carlos de Moya y Juan de Pareja ${ }^{\mathrm{IO2}}$. En la mayor parte de las ocasiones eran los propios dueños los que otorgaban los poderes para que los esclavos se vendieran fuera de la villa: así lo hicieron tanto Pedro Muñoz Briceño ${ }^{\mathrm{IO} 3}$ como Pedro Muñoz de Otálora ${ }^{\mathrm{I04}}$, su primo, en el año 1636.

En algunas ocasiones esto tipo de ventas fueran empleadas por los Muñoz de Otálora para castigar y penar supuestos comportamientos y actitudes desviadas de sus esclavos. La rebeldía, la desobediencia, los hurtos, los vicios y todo tipo de conductas alejadas de las normas dictadas por la familia y por la moral eran severamente castigadas. No se trataba de hacer negocio: los castigos y escarmientos eran empleados para dar ejemplo y para advertir al resto de siervos y criados sobre las consecuencias de las conductas y procederes no deseados por la familia. Los más frecuentes fueron los castigos corporales y las ventas a personas o a instituciones reales con fines de trabajos forzados.

\footnotetext{
98. MOUlier Boutang, (2006): 191

99. CASARES, (2014): 58

100. AGM. Not. 7266, fols. 269r. Traspaso de esclava de Pedro Muñoz de Otálora.

101. AGM. Not. 7273, fols. 265r/266v. Venta de esclavo de Pedro Jacinto Muñoz de Otálora.

102. AGM. Not. 7274, fols. 22v/24r. Poder de Francisco Gallego, administrador de la hacienda de Francisco Musso.

103. AGM. Not. 7275, fols 671r/v. Poder de Pedro Muñoz Briceño para vender un esclavo.

104. AGM. Not. 7275, fols. 1049r/v. Poder de Pedro Muñoz de Otálora al licenciado Jorge Pérez Baladejo para vender un esclavo.
} 
Un ejemplo significativo de esta última pena lo encontramos en el año i630: Pedro Muñoz de Otálora, regidor de la villa, dio poder a Martín Guerrero, vecino de Caravaca, para que vendiera «en las reales galeras de su majestad para que sirva a el remo» un esclavo heredado de su padre llamado Juan, prohibiendo taxativamente

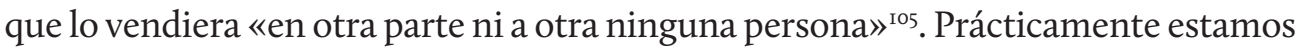
ante una condena a galeras. Lo cierto es que la rebeldía de los esclavos también fue duramente penada por las instituciones del reino. Con relativa frecuencia sufrieron condenas de reclusión en instituciones religiosas o pena de trabajos forzados en los reales arsenales, como evidencian numerosos casos del Madrid borbónico ${ }^{\mathrm{Io}}$. En el siglo XVIII, los denominados esclavos incorregibles eran puestos a disposición de la justicia solicitando con frecuencia la pena de galeras, práctica que incluso ejercerían hasta lo miembros de la familia real ${ }^{107}$.Las supuestas «faltas y delitos» contra la moral eran castigadas de manera más liviana, aunque algunos propietarios de esclavos también emplearon las ventas a particulares: Juan Bernard, por ejemplo, vendió a Francisco de Molina Muñoz, vecino de Cazorla, una esclava berberisca llamada María a la que calificaba de «puta, ladrona y borracha» por precio de I40 ducados ${ }^{108}$.

Las compras de esclavos responden a necesidades específicas de la familia. Rodrigo Muñoz, apoderado de Isidro de Lorca, jurado de la ciudad de Murcia, vendió en I590 dos esclavas en la villa de Caravaca: Ángela, de color blanco, cristiana bautizada, de tan solo trece años de edad, fue comprada por Fernando de Fuensalida en precio de 106 ducados; Axica, mora de veinte años, con una flor en la barba a manera de hierro, fue comprada por Francisco Musso Muñoz de Otálora en precio de I03 ducados ${ }^{109}$. Más ejemplos: En I629, Pedro Muñoz de Otálora compró a Pascual Martínez, natural de Elche, una esclava berberisca llamada Ana, de i8 años de edad, en precio de 245 ducados, la cual había comprado de Fernando de Parrega, vecino de Mula, «habida en buena guerra» y sin tachas ni defectos: no era «ni borracha ni ladrona» ${ }^{\text {II }}$. Las reventas de esclavos eran ciertamente frecuentes: Jerónimo de Nequesa, platero de oro, apoderado de Baltasar de Barea, asimismo platero de oro, vecino de Granada, vendió a Pedro Muñoz Briceño de Otálora, alférez mayor de la villa, un esclava berberisca llamada Francisca, de io años de edad, en precio de I9oo reales, la cual había adquirido previamente de Juan de Matute, mesonero de la ciudad de Antequera ${ }^{\text {III }}$.

Lo más habitual en la familia fue la propia crianza de esclavos en la villa de Caravaca y, en menor medida, la adquisición mediante la guerra, especialmente en los rebatos de la costa del reino de Murcia. Los Muñoces ejercieron en diversas ocasiones el oficio de capitanes de la milicia de la villa y además tenían facultad para nombrar al alférez de la compañía: no es casual que los registros de bautismo de algunos de sus esclavos coincidan en mayor o menor grado con las peticiones

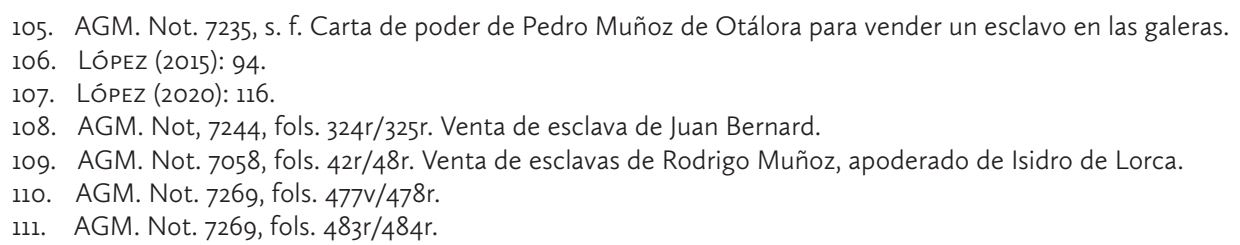


de auxilio del Capitán General del reino. No era algo novedosos: muchas familias de la villa de Caravaca consiguieron numerosos esclavos durante la Guerra de las Alpujarras: en I580, Pedro Muñoz, fiel ejecutor de la villa, dejó en libertad a dos de estas moriscas granadinas:

Yten, declaro que Costança y María, mis esclabas que obe de la guerra del reyno de Granada, por lo dispuesto por su magestad en la edad son libres, mando que se les de la libertad sin pleito alguno, con sus vestidos ${ }^{112}$.

La esclavitud de turcos y berberiscos mediante acciones de guerra tuvo su continuidad con la cautividad y esclavización de los moriscos apresados durante la rebelión del año 1568 , provocando un notable incremento de este tipo de comercio, caso de Almería ${ }^{\mathrm{II}}$. En Caravaca apreciamos el mismo aumento de la masa de población esclava, tanto a partir de los registros parroquiales como de las escrituras notariales. La rebelión de las Alpujarras propició una drástica reducción del precio de los siervos, permitiendo el acceso de personas con recursos limitados a un mercado reservado en un principio a personas con alto poder adquisitivo: la nobleza, los hidalgos, el clero, etc. ${ }^{\text {II4 }}$. En Caravaca también accedieron al mercado esclavista en el siglo XVI los mesoneros, los artesanos y los plateros. En el cercano reino de Granada, la mano de obra de esclavos berberiscos procedía de las cabalgadas, de la piratería, del corso y de la denominada «guerra justa» derivada de la ocupación de plazas norteafricanas, mientras que la población esclava negra, adquirida principalmente mediante el comercio, era originaria de Santo Tomé, de Cabo Verde y de Guinea (África occidental Subsahariana) ${ }^{\text {II }}$. Los esclavos finalmente desembarcaban en las Canarias, o bien eran llevados desde Orán y Melilla hasta los puertos de Cartagena y Málaga ${ }^{\mathrm{II} 6}$.

Resulta imposible precisar el número total de esclavos que poseyó la familia, aunque sin género de dudas fueron muchos, como evidencian los registros parroquiales y los documentos notariales. Los berberiscos fueron muy numerosos en la familia, especialmente tras el levantamiento de las Alpujarras. Los negros también abundaron entre los Muñoces y entre el resto de familias esclavistas de la villa de Caravaca, al igual que los denominados esclavos blancos, aunque el número de unos y otros descendió drásticamente a partir de la segunda mitad del siglo XVII, a consecuencia del encarecimiento de su precio motivado por el desabastecimiento, la sublevación portuguesa y la caída del poderío naval español ${ }^{117}$. A pesar de todo, la familia Muñoz de Otálora seguiría manteniendo esclavos hasta finales del siglo: Francisco Musso Muñoz de Otálora otorgó poder en i69I a Francisco Burruezo para que vendiera un esclavo llamado José de Santa María ${ }^{\text {II8 }}$ y en I7II compró a José de

112. AGM. Not.7273, fols. 175r/181r.Testamento de Isabel Muñoz.

113. ANDÚJAR, (1992-1993): 81-101.

114. VINCENT, (2008), 49.

115. MARTÍN, (1998): 337-348

116. VINCENT, (2008): 49

117. TORRES, (1986): 81-102.

118. AGM. Not. 7398, fols 145r/v. Poder de Francisco Musso Muñoz para vender un esclavo. 
Cantos, vecinos de Almansa, un esclavo llamado Antonio de la Cruz, de veinticuatro años, de pelo rojo y mediana estatura ${ }^{\text {II }}$.

La familia Muñoz de Otálora procuro catequizar y bautizar a sus esclavos, proporcionándoles una formación acorde con los «valores cristianos», aunque no siempre pudieran evitar que sus siervos tuvieran problemas con el Santo Oficio de la Inquisición: García Delgado, morisco granadino, esclavo de Diego López Baladejo, yerno de Francisco Musso Muñoz, fue prendido por negar la existencia del infierno y castigado a recibir cien azotes y a abjurar de vehementi en el auto de fe celebrado en la ciudad de Murcia en el año I586. Al parecer dijo a algunas personas que «no creyesen que avía infierno, que era por poner miedo a los neçios, que todo era gloria después de muertos» ${ }^{120}$. En otras ocasiones, no obstante, los esclavos de la familia pudieron evitar la acción inquisitorial: Ángela, cristiana nueva de mora, esclava de Pedro Muñoz, fue absuelta de los delitos que se le imputaban por haber dicho supuestamente «que era mora y siempre lo avía sido y que mora abía de morir» ${ }^{121}$.

Los esclavos de la familia se encargan de realizar las tareas más duras, tanto en la casa como en las haciendas de la huerta y del campo de la villa. Algunos estudios reivindican el duro trabajo doméstico realizado por las esclavas: servicio de cocina, lavar, almidonar y planchar la ropa, coser, etc ${ }^{122}$. En el caso de los Muñoz de Otálora parece claro que sus esclavas, además de ejercer este tipo de tareas, también se dedicaban a coser, tejer e hilar, tal y como evidencia la documentación consultada. El tratamiento que las familias esclavistas dispensaban a sus siervos no siempre fue bueno. En algunas ocasiones lo esclavos eran sometidos a continuas vejaciones y a duros castigos: el licenciado Pedro Muñoz se vio obligado a liberar a Jusepa, su esclava, «porque no la mate mi hijo don Pedro Muñoz, la qual dicha Jusepa me a servido bien», aunque finalmente acabó vendiéndola a Gonzalo Muñoz en precio de ciento veinte ducados, seguramente para protegerla.

No obstante, el tratamiento a los esclavos y la confianza en su honestidad y fidelidad guardaban estrecha relación con el honor y con las virtudes asociados al buen caballero. Gonzalo Muñoz dejó instrucciones en su testamento para que sus herederos no molestasen ni vejasen a sus esclavos:

Y porque me temo que mis herederos an de conpeler y apremiar a las dichas mis esclavas y esclavos a que declaren si me an tomado alguna cosa y que juren contra algunas personas que les an ayudado a ello y no es justo que a los criados ni esclavos de caballeros, como yo y de mi calidad, por cosas de poca consideración sean molestados, mando, quiero y es mi boluntad que en razón de lo susodicho ni de qualquiera cosa que me ayan tomado no se les veje, moleste ni agan a los tratamientos ni la justizia en razón dello de ofiçio ni pedimiento de parte no les conpela ni apremie a que agan ninguna declaraçión con juramento ${ }^{123}$

\footnotetext{
119. AGM. Not. 7431, fols. 268r/269v. Venta de un esclavo a Francisco Musso Muñoz

120. AHN. Inquisición. Leg. 2022, Exp. 17.

121. AHN. Inquisición. Leg. 2022, Exp. 4.

122. CASARES, (2014): 66.

123. AGM. Not. 7350, fols. 91r/116v. Testamento de Gonzalo Muñoz.
} 
Era frecuente que los Musso Muñoz y los Muñoz de Otálora dieran libertar a sus esclavos como medio para redimir el alma, purgar los pecados y recompensar los buenos servicios prestados durante años: Francisco Musso y Catalina Díaz de Villalta, por ejemplo, dieron libertad en 1572 a una de sus esclavas y a sus hijos:

María, madre de Juanico y Marco, nuestros esclavos de color blanco, por buenos servicios que nos an fecho y por amor que les tenemos y porque son christianos y por otras caussas que a ello nos mueven, sean libres y orros de toda servidumbre después de muertos nossotros dos ${ }^{124}$.

Las liberaciones eran ciertamente escasas, pese a que los esclavos alcanzaban relativamente grandes porcentajes en las grandes urbes ibéricas de la fachada atlántica. En Lisboa, Sevilla y Cádiz, a principios del siglo XVI, se calcula que un Io\% del total de la población era esclava ${ }^{125}$. En Badajoz, según datos proporcionados por Periáñez, durante los siglos del periodo moderno tan solo fueron liberados un total de 233 personas, cifra escasa si consideramos el número total de ventas y de nacimientos $^{126}$. En Sevilla y Jaén ocurría algo parecido. Además, es necesario precisar que muchos de los libertos eran ancianos o niños, poco productivos ${ }^{127}$. En Caravaca podemos considerar que tampoco fueron muy frecuentes, aunque la familia Muñoz procuró liberar a sus siervos prácticamente en casi todas las generaciones. Gonzalo Muñoz, regidor de la villa de Caravaca, otorgó libertad y carta de ahorría en favor de Cristóbal, su esclavo:

A Xptoval, mi esclavo, lo dejo libre y orro de servidumbre y mando que todos sus vestidos y ropa, con un cofrecillo en que la tiene, se le entregue y se la den. Y si hubiere de servir después de mis días algunas personas le encargo que sea a mis hijos y no a otro, pagándole servicio, lo qual ago por el buen servicio que me a echo ${ }^{128}$.

Lo cierto es que la manumisión de esclavos en el momento de otorgar testamento fue una constante en la familia, aunque también emplearon las típicas cartas de ahorría: en i625 el capitán Gonzalo Muñoz Girón dio libertad a Francisca, esclava que anteriormente había pertenecido a su suegro ${ }^{129}$. En algunas ocasiones también hicieron legados y mandas testamentarias para evitar, en la medida de lo posible, que quedaran desamparados, irremediablemente abocados a la pobreza o desprovistos de los más elementales medios de subsistencia. Catalina López Muñoz, viuda de Francisco Musso Muñoz de Otálora, por ejemplo, otorgó carta de ahorría a Ana, su esclava, y además dejó instrucciones para que le entregaran una cama, toda su ropa de vestir y un telar para que pudiera ganarse honradamente la vida:

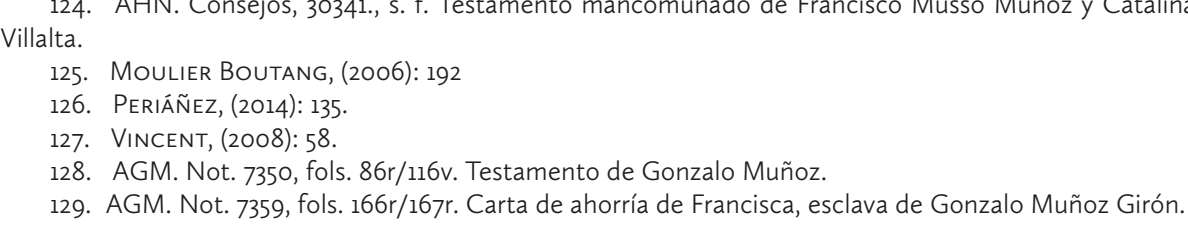


Iten, quiero i es mi voluntad que Ana, mi esclava, luego como io muera sea libre i se le dé su cama con toda su ropa de ella i la de bestir i su arca con lo que tuviere en ella i un telar i todo es lo se le dé a la dicha, sin que nadie se lo pueda inpediri3o.

Otros legados eran más modestos y eran empleados para recompensar los servicios prestados. Isabel Muñoz, hermana del licenciado Pedro Muñoz dispuso por su testamento que se dieran ciertos dineros de su hacienda a tres de sus esclavas, seguramente de origen granadino:

Yten, mando se den de mis bienes y haçienda a María, mi esclava, diez ducados, y a Brianda, tanbién mi esclava, otros diez ducados, y a Luisa, tanbién mi esclaba, que a los veinte años es libre, otros diez ducados ${ }^{131}$.

Otras mandas estaban especialmente orientadas a la representación pública del luto y del duelo por la muerte del señor, al igual que solían hacer los poderosos con sus criados y con los familiares y allegados más pobres de la familia o del linaje. Un típico ejemplo lo encontramos en el testamento del capitán Gonzalo Muñoz Girón, regidor de la villa de Caravaca, otorgado en i606:

Yten, mando a los demás criados y esclavos que estuvieren en mi serviçio al tienpo que yo fallezca se les haga de bestir capuzes y sotanas, ques un luto entero'132.

Los esclavos formaban parte de la familia y de la casa y en ocasiones mantenían relaciones muy cercanas con sus amos, semejantes a la del resto de criados, aunque siempre con las interpuestas barreras del estatus y de la jerarquía. Jacinto, esclavo negro de Pedro Muñoz Briceño, ejercía de escudero de su amo y en más de una ocasión participó en las luchas banderizas que los Muñoz de Otálora mantuvieron con el resto de familias de poder de la villa: en I630 participó en el duelo que la familia mantuvo con los Moya y sus aliados, hecho por el cual fue condenado a muerte por el licenciado Barrientos, juez de comisión.

La vinculación de los esclavos con la familia Muñoz de Otálora era tan fuerte que en ocasiones incluso persistía después de haber ganado la carta de libertad. Francisco, negro atizado, esclavo que fue del licenciado Pedro Muñoz de Otálora, dispuso por su testamento que su cuerpo se enterrase en la peana de la capilla que los Muñoces poseían en la iglesia parroquial de la villa, lugar donde se enterraban sus criados:

Yten, mando mi cuerpo sea sepultado en la peana de la capilla y bóbeda que tiene don Pedro Muñoz de Otálora alférez mayor que es en la iglesia mayor desta villa, donde se entierran los criados del dicho don Pedro ${ }^{133}$

La dependencia entre los libertos y sus antiguos amos era sobre todo económica: Francisco dispuso por su testamento que Pedro Muñoz de Otálora se encargase de disponer todo lo relativo a las misas y demás cuestiones referentes a la salvación de su alma: "para que haga en ello lo que quisiere y como cristiano y caballero que

\footnotetext{
130. AGM. Not. 7274, fols. 427r/438v. Testamento de Catalina López Muñoz.

131. AGM. Not. 7055, fols. 331r/341r. Testamento del licenciado Pedro Muñoz.

132. AGM. Not. 7206, fols. 119r/123v. Testamento del capitán Gonzalo Muñoz Girón.

133. AGM. Not. 7055, fols. 407r/408v. Testamento de Francisco, esclavo del licenciado Pedro Muñoz.
} 
es, atento yo no tengo bienes ningunos». Lo cierto es que Pedro Muñoz de Otálora impuso como condición para otorgar la carta de ahorría que Francisco le dejase como heredero de todos los bienes que adquiriese durante el tiempo de su libertad.

Los Muñoz de Otálora también consiguieron mantener la vinculación y dependencia de los libertos asegurándose el servicio a la familia en calidad de criados. Los libertos pasaban a forma parte del servicio doméstico de la casa a cambio de un salario semejante al que cobraban el resto de sirvientes: se trataba de una fórmula idónea para asegurar las fidelidades personales y un buen medio para garantizar la subsistencia durante la vida en libertad. Así lo hizo, por ejemplo, Francisco Musso Muñoz de Otálora en el año I624 con una de sus esclavas:

Yten, declaro que yo tengo amor y boluntad a María, mi esclava, por los buenos servicios que me a hecho, y en gratificación dellos la dexo libre y horra para que después de yo muerto haga de su persona lo que le pareciere, porque desde luego para estonçes (sic) me aparto del derecho de patronato que contra ella tengo, con que sirva a la dicha doña Catalina Muñoz, mi muger, mientras bibiere, con tanto que se le pague su salario como a una criada de mi cassa ${ }^{134}$

Las relaciones de los Muñoz de Otálora con sus siervas fueron semejantes a las que mantuvieron el resto de familias esclavistas. Las mujeres eran sometidas con frecuencia a las agresiones sexuales y a las vejaciones del amo y de su prole. Los esclavos precisaban del permiso del amo para poder contraer matrimonio, quedando la teórica libertad de elección de cónyuge que les otorgaba la legislación eclesiástica ciertamente limitada ${ }^{135}$. No obstante, en ocasiones los esclavos contraían matrimonio sin obtener la preceptiva licencia del amo: Catalina Musso Muñoz, viuda de Diego Ruiz Melgarejo, denunciaba en I602 que Pedro Melgarejo, su esclavo, «huyó de mi casa y se casó sin mi liçençia porque yo no le ahorré ni di libertad», circunstancia por la cual reclamaba los 40 ducados en que estaba tasado ${ }^{136}$.

No había leyes que prohibieran la unión de un esclavo con una persona libre, pero lo más normal era que tomaran estado con aquellos que poseían su misma condición social. Era muy frecuente, en este sentido, que los siervos buscaran cónyuge o pareja entre los propios esclavos o criados que habitaban en las casas de su amo. La convivencia bajo el mismo techo, aunque parece no era un factor determinante, favorecía la descendencia ${ }^{137}$. Las relaciones afectivas y sexuales de los esclavos discurrían con frecuencia fuera del matrimonio. La ilegitimidad era un factor predominante, tanto en Caravaca como en otras poblaciones, como evidencia los casos extremeños ${ }^{138}$ o gaditanos, entre otros.

Las relaciones que los amos y los restantes varones que habitaban en las casas mantenían con las esclavas eran en la mayor parte de los casos forzadas, teniendo

134. AGM. Not. 7263, fols. 29r/33v. Testamento cerrado de Francisco Musso Muñoz de Otálora.

135. VINCENT (1997): 31-39.

136. AMCa. Fondo de los Condes del Valle de San Juan. CAR. L. 4. Nº 29. Testamentos y codicilos de Catalina Musso Muñoz.

137. MORGADO, (2012): 67-81.

138. Periañez, (2010). Para el caso concreto de Llerena, donde la ilegitimad alcanza un porcentaje del 97,1, consúltese PERIAÑEZ, (2013): 287-299. 
como consecuencia el nacimiento de criaturas en cautiverio. No era raro que los señores tuvieran hijos con sus siervas: los niños nacidos de estas uniones reproducían la condición social de la madre y para algunos personajes sin escrúpulos no dejaba de ser una fórmula más para aumentar su patrimonio. La mercantilización de las esclavas, por tanto, no estaba motivada exclusivamente por el beneficio obtenido en base al recurso de la mano de obra productiva, sino que también debemos entenderla como un intento de apropiarse de sus cuerpos y de sus derechos sexuales y reproductivos ${ }^{139}$. Otras veces, las relaciones entre amo y sierva eran consénsuales e incluso con el tiempo llegaban a convertirse en afectivas. Un ejemplo significativo lo encontramos en el caso del doctor Calvete, regidor de la villa de Caravaca, que vivió, pese a las denuncias del alcalde mayor y de las familias rivales, amancebado durante años con una de sus esclavas con la que llegó a procrear, al menos, cuatro hijas.

Este tipo de comportamientos también están presentes en la familia Muñoz de Otálora. El licenciado Pedro Muñoz, alférez mayor de la villa, tuvo un hijo con una de sus esclavas berberiscas, aunque nos resulta imposible precisar si estamos ante una práctica habitual o simplemente ante un caso aislado. La presencia de esclavos blancos en las casas de la familia podría ser un indicativo de esta práctica cultural, pero también podría estar motivada por otros factores sociales: relaciones con los criados de la casa o con otros vecinos de la villa e incluso granadinos. El capitán Sahajosa, yerno de Pedro Muñoz, dispuso por su testamento que sus herederos pusieran en libertad a Juanico, su esclavo, si Antón Pérez u otra persona pagaban los treinta ducados de su tasación: «porque diçen ques su hijo».

La libertad de los hijos nacidos en cautiverio debió de ser una práctica habitual, al menos entre las personas con un mínimo de escrúpulos, aunque la relación de parentesco no siempre quedara de manifiesto en la documentación. Los Muñoz de Otálora no fueron una excepción: el licenciado Pedro Muñoz dejó en libertad en I595 a Baltasar de Villalta, su hijo, y además dio instrucciones precisas a sus herederos para procurarle un medio de subsistencia digno:

\begin{abstract}
y que el dicho don Pedro Muñoz, mi hijo mayor, u otro poseedor de los mayorazgos de mis padres y mío, le provean de la capellanía de don Alonso Muñoz, mi hermano, para ordenarse. Y desde luego dexo nombrado por capellán de la dicha capellanía al dicho Baltasar de Villalta, y si en mis días no quedare ordenado de misa encargo al dicho don Pedro Muñoz lo haga ordenar y le de la dicha capellanía y gaste con el dicho Baltasar de Villalta hasta que aya cantado misa. Y demás de la dicha capellanía le dexo al dicho Baltasar de Villalta, después de mis días, la casa en que bibe Carboneras en la corredera para que biba en ellas durante su vida y después de su muerte benga a mis herederos ${ }^{140}$.
\end{abstract}

No obstante, Baltasar de Villalta rechazó la carrera eclesiástica y las rentas de la capellanía de Alonso Muñoz, alistándose finalmente como soldado en la milicia para servir al rey en las guerras de Flandes e Italia.

139. Delicado-Moratalla, (2017): 1334-1360.

140. AGM. Not. 7055, fols. 331r/341r. Testamento del licenciado Pedro Muñoz. 


\section{CONCLUSIONES}

Los Muñoz de Otálora emplearon a sus criados y esclavos como símbolos exteriores del estatus y del honor del linaje, pero también como elementos esenciales en la producción y en la economía de la familia. Las tierras que no eran entregadas en arrendamiento eran cultivadas y trabajadas por los propios esclavos y criados de la familia, así como por un gran número de jornaleros de Caravaca y de las villas vecinas. Los ganados eran gobernados y pastoreados por mayorales, manaderos, hateros y zagales. Podemos afirmar que los Muñoz de Otálora mantuvieron relaciones de clientelismo y de patronazgo durante generaciones con algunos de los jornaleros y pastores que labraban sus tierras y cuidaban de sus ganados. El artículo ilustra el ascenso en la jerarquía de la servidumbre a través del ejemplo de Juan Martínez Andrada, personaje que supo ganarse el favor y la confianza de su amo para convertirse en su mayordomo y amasar una pequeña fortuna que emplearía para adquirir algunas tierras en Lorca y en Caravaca. La economía familiar precisaba también de numerosos trabajadores especializados, como arrieros y maestros de hacer carros, que trabajaban prácticamente en exclusiva para la familia. Los agregados domésticos también fueron muy numerosos en la familia, aunque nos resulta imposible precisar su número exacto, nos consta la presencia de mayordomos, amas de llaves, amas de cría y de simples criados. Algunos documentos también distinguen entre «criados de escalares arriba» $\mathrm{y}$ «criados de escaleras abajo». En Caravaca también se diferenciaba entre dos tipos de criadas: «la mujer hecha y las muchachas», variando el salario a percibir en función de la edad. Solían ser huérfanas o hijas de viudas y lo más frecuente era que entraran a servir con doce o catorce años y que el contrato se prolongara durante seis u ocho años, lo suficiente para adquirir una dote o ayudar a la economía familiar.

En cuanto a los esclavos, siempre fueron muy numerosos en la familia Muñoz de Otálora, especialmente tras la rebelión de las Alpujarras, constando la presencia de berberiscos, granadinos, negros, mulatos y blancos. La familia procuró catequizar y educar a sus esclavos en los valores cristianos, intentado, asimismo, purgar los pecados y redimir el alma mediante diversos legados y otorgando libertad por disposición testamentaria. También emplearon con frecuencia las cartas de ahorría y procuraron proteger a sus libertos asociándolos como asalariados a la casa $\mathrm{o}$ proporcionándoles las herramientas y útiles necesarios para realizar sus trabajos cotidianos. También emplearon los castigos corporales y la condena a galeras para los esclavos incorregibles, mantuvieron relaciones sexuales con sus esclavas e incluso llegaron a procrear hijos. En definitiva, los Muñoz de Otálora emplearon sus recursos económicos para rodearse de esclavos y criados con el fin de mostrar el poderío y la magnificencia de la familia, pero también fueron empleados como esenciales elementos productivos. 


\section{BIBLIOGRAFÍA}

Andújar Castillo, Francisco. «Del esclavo morisco al berberisco: sobre la esclavitud en la Almería del siglo XVIII», Boletín del Instituto de Estudios Almeriense. Letras, no II-I2. (I992-I993): 8I-IOI.

Aragón Mateos, Santiago. «Amos y criados en la Extremadura dieciochesca», Actas del Congreso Internacional sobre «Carlos Ill y la Ilustración». Tomo Il. Economía y sociedad, 403-424. Madrid. I989.

Blanco CARrasco, José Pablo. «Criados y servidumbre en España durante la Época Moderna: reflexiones en torno a su volumen y distribución espacial a finales del Antiguo Régimen. Investigaciones históricas: Época moderna y contemporánea, no 36, (2016): 4I-80.

Bolufer Peruga, Mónica. «Actitudes y discursos sobre la maternidad en la España del siglo XVIII: la cuestión de la lactancia», en Historia Social, n ${ }^{\circ}$ I4, (I992): 3-22.

BoudjaAba, Fabrice \& García GonzÁlez, Francisco. «Dossier: El trabajo doméstico y sirviente en la Europa rural (SS. XVI-XIX). Diversidad de modelos regionales y formas de dependencia» en Mundo Agrario, vol. I8, nº 39, (20I7):

BoudjAABA, Fabrice \& Hermente, Laurent. «Travail domestique et travail salarié des enfants dans le monde rural (le canton de Marines vers i830)», en Mundo Agrario, vol. I8, n 39 , (20I7): eo68.

Carrasco Martínez, Adolfo. «Señores y criados. La servidumbre de la aristocracia en el siglo XVIIl». Mentalidad e ideología en el Antiguo Régimen. Actas de la II Reunión Científica de la Asociación Española de Historia Moderna, Vol. Il, editado por Álvarez Santaló, León Carlos y Cremades Griñán, Carmen María, 203-209.Murcia: Universidad de Murcia, I992.

Chacón Jiménez, Francisco. «Familia, casa y hogar. Una aproximación a la definición y realidad de la organización social española (Siglos XIII-XX)». Espacios sociales, universos familiares. La familia en la historiografía española, editado por Francisco Chacón Jiménez y Juan Hernández Franco, 5I-66. Murcia: Universidad de Murcia, 2007.

Chacón Jiménez, Francisco. «Reflexiones sobre Historia y movilidad social». Poder y movilidad social. Cortesanos, religiosos y oligarquías en la Península Ibérica (siglos XV-XIX), editado por Francisco Chacón Jiménez y Nuno Gonçalo Monteiro, 43-58. Madrid: C.S.I.C., 2006.

Delicado-Moratalla, Lydia. «Esclavitud, género y racialización en Alicante: la colonización de los cuerpos femeninos (ss. XVII-XVIII), en Géneros Ejemplar dedicado a: Géneros. Multidisciplinary Journal of Gender Studies, Vol. 6, $\mathrm{n}^{\mathrm{0}}$ 2. (2017): 1334-1360.

Donézar Díez de Ulzurrun, Javier María. Riqueza y propiedad en la Castilla del Antiguo Régimen. La provincia de Toledo en el siglo XVIII. Madrid, I984.

Dubert GARCíA, Isidro. (2005): «Criados, estructura económica y social y mercado de trabajo en Galicia rural a finales del Antiguo Régimen», en Historia Agraria: Revista de agricultura e historia rural, $\mathrm{n}^{\mathrm{O}}$ 35, (2005): 9-26.

Dubert García, Isidro. «Composición, salarios y promoción social en el servicio doméstico rural de la Galicia interior, I700-I825», en Mundo Agrario, vol. I8, nº 39, (2017): I-I9.

EsPINILla SANZ, Beatriz. «La elección de las nodrizas en las clases altas, del siglo XVII al XIX, en Matronas profesión, vol. I9, (2013): 68-73.

Fauve-Chamoux, Antoinette. «Etat de la question. L 'apport de l' historiographie internationale», en Sextan, «Domesticité». Vol. I5-I6, Gubin Éliane y Piette Valérie ediciones, (200I): 9-3I. 
Fauve-Chamoux, Antoinette. «Domesticité et parcours de vie. Servitude, service premarital ou métier?, en Annales de démographie historique, $\mathrm{n}^{\mathrm{O}}$ II7, (2009): 5-34.

Fernández García, Francisco. Historias de Caravaca, Ayuntamiento de Caravaca y La Tribuna del Noroeste, Caravaca, 2015.

García GonZÁlez, Francisco. «Sirvientes y criados en el mundo rural de la España interior, I700-I860: desigualdad social y dependencia», en Mundo Agrario: Revista de estudios rurales, vol. I8, $\mathrm{n}^{\circ}$ 39, (2017): I-22.

GARRIDO ARCE, Estrella. «El trabajo de las mujeres en la economía familiar preindustrial. La huerta de Valencia en el siglo XVIIl», Actas del Congreso Internacional del Seminario de Estudios Interdisciplinarios de la Mujer, coordinado por Ramos Palomo, Dolores y Vera Balanza, María Teresa, I05-II6.Málaga: 1996.

GonZÁlez Beltrán, Jesús Manuel. «Desempleo y pobreza en la agricultura de la Baja Andalucía en el siglo XVIIl». Chronica nova: Revista de historia moderna de la Universidad de Granada, ${ }^{\mathrm{o}} 37$, (2011): 237-270.

Guillén BerRendero, José Antonio. Los Mecanismos del honor y la nobleza en Castilla y Portugal, I556-I62I, Tesis doctoral dirigida por Adolfo Carrasco Martínez. 2009.

Hernández Franco, Juan \& Rodríguez PÉrez, Raimundo Antonio. «El linaje se transforma en casa: de los Fajardo a los marqueses de los Vélez y de Espinardo». Hispania: Revista española de historia, vol. 74, $\mathrm{n}^{\circ}$ 247. (2014): 385-410.

Hernández Franco, Juan. y Quiñonero Gómez, Manuel. «La cuestión de los vagos. en Lorca entre I755-1800». Contrastes: Revista de historia moderna, $\mathrm{N}^{\circ}$ I, (I985): 73-96.

Hidalgo Fernández, Francisco. «Hacia una prosopografía de los artífices plateros malagueños a partir del catastro de Ensenada». Hacer historia moderna: Líneas actuales y futuras de investigación, coordinado por Iglesias Rodríguez, Juan José y Melero Muñoz, Isabel, 304-3I8. Sevilla: Universidad de Sevilla, 2020.

Jover Avellá, Gabriel, PujadAs-Mora, Joana-María \& SuAU, Ana María. «¿Quiénes eran los mozos en las regiones mediterráneas? Salarios y movilidad de los mozos en el mercado de trabajo en Mallorca, I654-I680», en Mundo Agrario: Revista de estudios rurales, vol. I8, $\mathrm{n}^{\mathrm{o}}$ 39, (2017): I-20.

IRIGOYEN LÓPEZ, Antonio: «Aproximación al estudio del servicio doméstico del alto clero de Murcia durante el siglo XVIII, en Obradoiro de historia moderna, $\mathrm{n}^{\circ}$ I9, (2010):307-327.

López García, José Miguel. «Rebeldes con causa. Los esclavos incorregible en el Madrid borbónico», en Esclavitud, mestizaje y abolicionismo en los mundos hispánicos, coordinado por Aurelia Martín Casares, (2015): 285-306.

López García, José Miguel. La esclavitud a finales del Antiguo Régimen. Madrid. I70I-I837. De moros de presa a negros de nación. Alianza Editorial, 2020.

Lorenzo PINAR, Francisco Javier. «Los criados salmantinos durante el siglo XVII (I6oII650): conflictividad social y actitudes ante la muerte». Obradoiro de historia moderna, $\mathrm{n}^{\mathrm{o}} \mathrm{I} 8,(2009): 233-26 \mathrm{I}$.

Lorenzo PINAR, Francisco Javier. «Los criados salmantinos durante el siglo XVII (I6oII650): conflictividad social y actitudes ante la muerte (II)», en Studia histórica. Historia moderna, $\mathrm{n}^{\mathrm{o}}$ 3I, (2009): 275-304.

Martín CASARES, Aurelia. «Esclavitud y mentalidad: la población esclava de Granada a lo largo del siglo XVI», Chronica nova: Revista de historia moderna de la Universidad de Granada, $\mathrm{n}^{\circ}$ 25. (I998): 337-348.

Martín Casares, Aurelia. «Productivas y silenciadas: el mundo laboral de las esclavas en España», Mujeres esclavas y abolicionistas en la España de los siglos XVI al XIX. editoras 
Periáñez Gómez, Rocío y Martín Casares, Aurelia, Madrid, Spain: Editorial lberoamericana. Vervuert. (20I4): 57-94.

Morgado García, Arturo. «La vida familiar de los esclavos en el Cádiz de la modernidad (I600-I750)». Trocadero: Revista de historia moderna y contemporánea, $\mathrm{n}^{0}$ 24. (2012): 67-8I.

Moulier-Boutang, Yann. De la esclavitud al trabajo asalariado. Economía histórica del trabajo asalariado embridado, Madrid, Akal, 2006.

Pérez Picazo, María Teresa. Caravaca de la Cruz I755. Según las Respuestas Generales del Catastro de Ensenada, Madrid, I993.

PeRIÁÑ̃z Gómez, María Rocío, «Los registros parroquiales: una fuente para el estudio de la esclavitud en Llerena.» La representación popular: historia y problemática actual y otros estudios sobre Extremadura, coordinado por Lorenzana de la Puente, Felipe, Iniesta Mena, Félix y Mateos Ascacíbar, Francisco J. Llerena: Sociedad Extremeña de historia, (2013): 287-299.

Periáñez Gómez, Rocío. «El acceso a la libertad de las esclavas: ¿liberación o distinta forma de sometimiento?», Mujeres esclavas y abolicionistas en la España de los siglos XVI al XIX. editoras Periáñez Gómez, Rocío y Martín Casares, Aurelia, Madrid, Spain: Editorial Iberoamericana. Vervuert. (2014): I34-I54.

Periáñez Gómez, María Rocío. Negros, mulatos y blancos: los esclavos en Extremadura durante la Edad Moderna, Badajoz: Diputación de Badajoz. Departamento de Publicaciones. 2010.

Pérez Picazo, María Teresa y Lemeunier, Guy. El proceso de modernización de la región murciana (siglos XVI-XIX), Biblioteca básica murciana, I984.

SÁNCHEZ GonZÁlez, Ramón. «Los criados de la nobleza: ordenanzas, instrucciones y registros contables». Monarquías en conflicto: linajes y noblezas en la articulación de la Monarquía Hispánica, coordinado José Ignacio Fortea Pérez, Juan Eloy Gelabert González, Rafael López Vela y Elena Postigo Castellanos, 815-824. Madrid: Fundación Española de Historia Moderna, Universidad de Cantabria, 2018.

SÁNCHEZ IbáÑEZ, Raquel. Linaje y poder: los parientes mayores de Verástegui (ss. XIV-XVIII). Murcia: Universidad de Murcia, 2012.

SARASÚA, Carmen. Criados, nodrizas y amos. El servicio doméstico en la formación del mercado de trabajo madrileño, I758-I868, Madrid. Siglo XXI. 1994.

SARTI, Raffaela. «Criados, servi, domestiques, gesinde, servants: for a comparative history of domestic service in Europe ( $\left(6^{\text {th }}-\mathrm{I}\right)^{\text {th }}$ centuries)», en Obradoiro de Historia Moderna, $\mathrm{n}^{\mathrm{o}} 39-9: 2007, \mathrm{I} 6$.

TORRes SÁncheZ, Rafael. «La esclavitud en Cartagena en los siglos XVIl y XVIII», en Contrastes: Revista de historia moderna, $\mathrm{n}^{\circ}$ 2. (I986): 8I-IO2.

Tovar Pulido, Raquel. «Nobleza rural andaluza. Hidalguías, rentas y servidumbre en el Siglo de las Luces». Hacer historia moderna: Líneas actuales y futuras de investigación, coordinado por Iglesias Rodríguez, Juan José y Melero Muñoz, Isabel, 442-454. Sevilla: Universidad de Sevilla, 2020.

VINCEnT, Bernard, «La vie affective des esclaves de la Péninsule Ibérique XVle-XIXe siècle, Familia y Mentalidades. Historia de la familia: una perspectiva sobre la sociedad Europea, editores Rodríguez Sánchez, Ángel, y Peñafiel Ramón, Antonio, 3I-39. Murcia: Universidad de Murcia, 1997.

VINCENT, Bernard, (2008), «La esclavitud en el Mediterráneo occidental (siglos XVI-XVIII)», Circulación de personas e intercambios comerciales en el Mediterráneo y en el Atlántico (siglos XVI, XVII y XVIII), director José Antonio Martínez Torres, Madrid, CSIC, (2008): 39-64. 


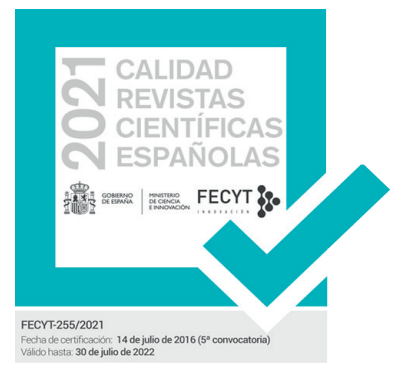

SERIE IV HISTORIA MODERNA

REVISTA DE LA FACULTAD DE GEOGRAFÍA E HISTORIA

AÑO 2021

ISSN: 1131-768X

E-ISSN 2340-1400

\section{4 \\ 西 ESPACIO, TIEMPO Y FORMA}

Monográfico - Special Issue: La política ultramarina de las monarquías ibéricas (circa 1700-1750): una historia de fracasos y éxitos relativos The Overseas Policy of the Iberian Monarchies (Circa 1700-1750): A History of Failures and Relative Successes

15 Roberto Quirós Rosado y MARIA FERnANDA BICALHO La política ultramarina de las monarquías ibéricas (circa 1700-1750): una historia de fracasos y éxitos relativos / The Overseas Policy of the Iberian Monarchies (Circa 1700-1750): A History of Failures and Relative Successes

\section{Guillaume Hanotin}

Defender negocios en tiempo de convulsión política: las elites mercantiles francesas durante la guerra de Sucesión española / Protecting Business in Time of Crisis: French Trademen during the War of Spanish Succession

\subsection{Maria Fernanda Bicalmo}

Ultramarino y el auge de los secretarios de Estado en Portugal durante la primera mitad del siglo XVIII / Sobre este modo de resolver e despachar os negócios. The decline of the Overseas Council and the Rise of the Secretaries of State in Portugal during the First Half of the $18^{\text {th }}$ Century

\section{9}

\section{VALENTINA FAVARò}

El fracaso de los proyectos de reforma en el virreinato peruano de principios

del siglo XVIII. Las propuestas de Carmine Nicola Caracciolo, príncipe de Santobuono the Eighteenth Century. The Proposals of Carmine Nicola Caracciolo, Prince of Santobuono

\section{7}

\section{ROBERTO QUIRÓS ROSADO}

Ecos de un mercantilismo truncado. El conde de Pinos Puente y la diplomacia comercial de Carlos VI en la corte de Lisboa (1723-1724) / Echoes of a Failed Mercantilism. The Count of Pinos Puente and the Commercial Diplomacy of Charles VI at the Court Of Lisbon (1723-1724)

\section{Junia Ferreira Furtado}

Portuguese America under Foreign Threat and the Creation of the Concept of uti possidetis in the First Half of the $18^{\text {th }}$ Century / La américa portuguesa bajo la amenaza exterior y la creación del concepto de uti possidetis en la primera mitad del siglo XVIII

\section{Miscelánea $\cdot$ Miscellany}

\section{José Antonio Mateos Royo}

con Cataluña / Trade Policy and Monetary Circulation in Aragon: Conflicts and Agreements with Catalonia (1535-1565)

\section{Fernando Altoé}

panegíricos atribuidos a la impresion. Un estudio de la trayectoria de dos the Trajectory of Two Panegyrics Attributed to João de Barros

\section{Francisco Velasco Hernández}

reino de Murcia (siglos XVI y XVII) / The Influence of the Berber Corsican on the Late Repopulation on the Coastal Area on the Kingdom of Murcia (XVI and XVII Centuries)

\section{José Antonio Martínez Martínez}

Criados, jornaleros y esclavos al servicio de la familia: la servidumbre de Serfdom of the Muñoz de Otálora in the $17^{\text {th }}$ Century

\section{Víctor Daniel Regalado González-Serna}

Benito de Medina a raíz de su ingreso en el cabildo catedral de Sevilla en 1669 / «Not a Single Good Portuguese». Accusations against Priest Alonso Benito de Medina when Entering the Cathedral Chapter of Seville in 1669

\section{José Herrera Reviriego}

organigrama comercial y militar de la Gober a tólo mitad del siglo XVII / "Only Time will Tell us»: The Role of Taiwan within the Commercial and Military Organization of the Philippine's Governoration during the First Half of the Seventeenth Century

\section{Manuel-Reyes García Hurtado}

de Rande, 1719-1733 / Vicissitudes of the Rescue Companies of the Sunken Ships in the Battle of Rande, 1719-1733

\subsection{Marcos de Miguel Muñoz}

Caballeros in 1769 


\section{4 ESPACIO, TIEMPO Y FORMA}

\section{Javier Tinoco Domínguez}

Tensiones sociopolíticas en el marco del catastro de Ensenada en Jerez de la Frontera: estudio de un conflicto institucional / Socio-Political Tensions within the Framework of Cadastre of Ensenada In Jerez de la Frontera: A Studying of an Institucional Conflict

\section{Pablo Fernández Albaladejo}

Fábulas de origen y gramática de nación en la España del siglo XVIII. A propósito de algunos trabajos de Francisco Martínez Marina / Origin's Fables and Grammar of Nation in the XVIII Century Spain. About some Works by Francisco Martínez Marina

\subsection{José María IÑURRITEgui Rodríguez}

Constitución increada: Francisco Martínez Marina y la crítica bíblica / Uncreated Constitution. Francisco Martínez Marina and Biblical Criticism

\subsection{David A. Abián Cubillo}

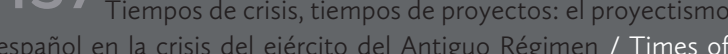
crisis, Times of Projects: The Spanish proyectismo during the Army's Crisis in the Ancient Regime

Taller de historiografía · Historiography Workshop

\section{Ensayos · Essays}

\subsection{ChrISTOPH ROSENMÜLLER}

«Tan peligrosas y feas conspiraciones»: la relación escrita por el embajador austriaco Christoph Migazzi en 1754 sobre la caída del marqués de la Ensenada / «Dangerous and Ugly Conspiracies». The Report of the Austrian Ambassador Christoph Migazzi on the Fall of the Marquis of la Ensenada in 1754

\subsection{Serge Gruzinskı}

Quelle histoire enseigner en 2021 ? / ¿Qué historia enseñar en 2021?

\subsection{Carlos Amate Pizarro}

Las relaciones hispano-chinas en el siglo XVI: síntesis e interpretación a la luz de la reciente historiografía / The Hispanic-chinese Relationship in the XVI Century: Synthesis and Interpretation in the Light of Recent Historiography

\section{Reseñas • Book Review}

521 Bolufer Peruga, Mónica, Arte y artificio de la vida en común. Los modelos de comportamiento y sus tensiones en el Siglo de las Luces, (Julio ArRoyo Vozmediano) 


\section{4 ESPACIO, TIEMPO Y FORMA}

525 Melón, Amando, Alejandro de Humboldt. Vida y obra (Carlos Martínez Shaw)

52 Commentary to Tatiana Seijas' review of The Atlantic World and the Manila Galleons: Circulation, Market, and Consumption of Asian Goods in the Spanish Empire (JosÉ LuIs GASCH TOMAS)

533 Braguier, Laurey, Servantes de dieu. Les beatas de la Couronne de Castille (1450-1600) (Manuela Águeda GARCÍA-GARRIDO)

539 Romeo, María CRuz; SAlomón, María Pilar; TABANERA, Nuria (eds.): Católicos, Reaccionarios y Nacionalistas. Política e identidad nacional en Europa y América Latina Contemporáneas (JAVIER M. Dos SANTOS)

54 Heredia López, Alfonso Jesús, El control de la corrupción en la Monarquía Hispánica. La Casa de la Contratación (1642-1660) (José Manuel Díaz Blanco)

17 Andújar Castillo, Francisco, El Atila de Madrid. La forja de un banquero en la crisis de la monarquía (1685-1715) (Aitor Díaz PAREdes)

551 Serrano Aviles, Javier y Mojarro, Jorge (eds.) Prada GonzALEZ, María (coord. de ilustraciones), En el archipiélago de la Especiería. España y Molucas en los siglos XVI y XVII (İ̃̃ıGo VALPUESTA VILLA)

555 Díaz Ceballos, Jorge, Poder compartido. Repúblicas urbanas, Monarquía y conversación en Castilla del Oro, 1508-1573 (JUAN SEbAstián Gómez GonZÁleZ)

51 Edelmayer, Friedrich, Massimiliano II, Filippo II I'Italia imperiale. II marchesato di Finale, i diritti imperiali e il «camino spagnolo» (RAFAEL VALLADARES)

56 Escribano-PÁEZ, José M., Juan Rena and the Frontiers of Spanish Empire, 1500-1540 (DAvid Martín Marcos)

56 ARnOLD, David, La Era de los Descubrimientos (1400-1600), Madrid, Alianza Editorial, 2021, 184 Pp., ISBN: 978-841362-172-2 (CARlos Amate Pizarro) 